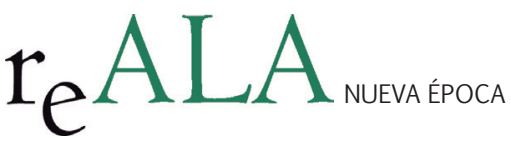

REALA, n 2, julio-diciembre 2014, ISSN: 1989-8975

DOI: http://dx.doi.org/10.24965/reala.voi2.10199

\title{
Sentido y orientación de la Ley 27/2013 de racionalización y sostenibilidad de la Administración local: autonomía local, recentralización y provisión de servicios públicos locales ${ }^{1}$
}

\author{
Andrés Boix Palop \\ Profesor de Derecho administrativo. Universitat de València - Estudi General \\ Andres.boix@uv.es
}

Recibido: 20 de mayo 20/4

Aceptado: 16 de junio 2014

\begin{abstract}
Resumen
El presente trabajo trata de identificar algunas de las líneas esenciales de la reforma local operada por la ley 27/2013 y analizar cómo, en concreto, es previsible que afecten a nuestro régimen local tradicional y a los fundamentos de su marco jurídico constitucional. En concreto, el estudio se centra en indagar en la efectiva posibilidad de que la noción de autonomía local permita predicar cierta capacidad de resistencia jurídica frente a las pretensiones de reforma del legislador, en primer lugar. También analiza la reforma local a partir de la identificación de una línea, rastreable ya desde hace unos años, tendente a limitar las posibilidades de desarrollo autonómico, esto es, de recentralización jurídica de la regulación sobre el régimen local. Por último, se estudian las consecuencias en materia de prestación de servicios públicos locales derivadas del cambio legal, explicándose las razones por las que se entiende que la nueva ley local, en el fondo, lo que pretende introducir son elementos favorecedores de una creciente privatización de los mismos.
\end{abstract}

Palabras clave

Reforma local, autonomía local, recentralización, régimen local, privatización, servicios públicos locales

\section{Main guidelines of the 27/2013 Spanish Act of Rationalization and Sustainability of Local Government about Local Autonomy, Recentralization and Provision of Local Public Services}

\section{Abstract}

This paper tries to identify some of the main guidelines underlying the Local Law reform made in Spain by law 27/2013 and to analyze how, in particular, this legislative change is expected to affect both the way our local governments had been acting since 1985 as well as the basic foundations of our constitutional framework in relation with local government. Specifically, the paper focuses on investigating whether the notion of local autonomy allows us to preach at least some legal resistance to the changes the 2013 reform is intending to make. It also analyzes the reform as a product of the trend, traceable in recent years, aimed to limit the possibilities of regional legislatures regulating local government, i.e. as a product and evidence of a legal recentralization process. Finally, the paper studies how local public services will be provided as a result of these legal changes, explaining how the new local law, in fact, is intended to introduce measures favoring increased privatization in the provision of local services.

Keywords

Local reform, local autonomy, recentralization, local government, privatization, local public services.

1 Este trabajo fue presentado inicialmente en el Seminari de la Facultat de Dret de València el pasado 27 de noviembre de 2013, cuando la Ley 27/2013, de racionalización y sostenibilidad de la Administración local, estaba todavía en proceso de tramitación parlamentaria. Una primera versión escrita, necesariamente incompleta y ayuna de muchas referencias, fue publicada con el título "Tres notas explicativas sobre el sentido y orientación de la Ley 27/2013 de racionalización y sostenibilidad de la Administración local: limitación de la autonomía local, recentralización y redefinición de los mercados de provisión de servicios sociales" por el Diario del Derecho Municipal de la editorial lustel del día 2 de enero de 2014 como primera reacción a la definitiva aprobación de la norma, que había aparecido en el Boletín Oficial del Estado del día 30 de diciembre de 2013. 


\title{
SUMARIO
}

\begin{abstract}
I. Génesis y principios de la reforma legal. II. Reforma del régimen local y debilidad de la garantía de la autonomía municipal. III. La reforma como mecanismo de redefinición en clave centralizadora de las competencias sobre régimen local. IV. Eficiencia y gestión de los servicios públicos locales: hacia un redimensionamiento de los mercados de servicios y la gestión privada de los mismos. V. Críticas al modelo plasmado en la ley de reforma local y a sus insuficiencias.
\end{abstract}

\section{GÉNESIS Y PRINCIPIOS DE LA REFORMA LEGAL}

La tramitación parlamentaria de la Ley de racionalización y sostenibilidad en la Administración Local (en adelante, LRSAL) ha resultado, como es sabido, mucho menos azarosa y complicada, merced a la sólida mayoría parlamentaria con la que cuenta el gobierno, que todo el proceso previo de elaboración de la norma. A los cambios sucesivos que fueron padeciendo los diversos borradores presentados durante meses por los órganos que han diseñado la reforma, encabezados por el Instituto Nacional de Administración Pública (INAP), se añadió el varapalo que el Consejo de Estado por medio de su Dictamen de 26 de junio de 2013 propinó al Anteproyecto de la norma (en adelante, ALRSAL) que finalmente había presentado el gobierno, lo que obligó a nuevas modificaciones. Finalmente, tras sucesivas rectificaciones, el texto remitido por el Gobierno como Proyecto de ley (en adelante, PLRSAL) ha acabado convirtiéndose, sin excesivas modificaciones de calado, en la ley finalmente aprobada en Cortes. Una norma, la ya referida LRSAL, Ley 27/2013, de 27 de diciembre, de racionalización y sostenibilidad de la Administración Local (publicada en el BOE del 30 de diciembre de 2013) que se parece muy poco o casi nada a las primeras propuestas lanzadas por el Gobierno. Básicamente porque, si bien muy criticable desde muchos puntos de vista, en los primeros borradores sí aparecía un modelo de régimen local diferenciado (muy limitador de la autonomía local, imponiendo transformaciones estructurales enormes y controles de todo tipo), mientras que la norma finalmente aprobada, aunque comparta las orientaciones de fondo, de tan diluida que ha quedado adolece de una manifiesta falta de visión sobre lo que quiere que sea el régimen local y es muy dudoso, por ello, que vaya a suponer realmente un cambio de verdadero calado respecto del régimen local español y sus perfiles básicos definidos como tales desde 1985, tal y como sus primeros comentaristas ya han señalado (Santamaría Pastor, 2014: 141-148, 154-155).

Conviene recordar que estas primeras propuestas, por mucho que es cierto que eran mucho más ambiciosas de lo que ha sido el resultado final y no podía negarse, en efecto, que contenían un "modelo de régimen local", fueron acogidas con enorme escepticismo por casi todos los especialistas en la materia y una gran mayoría de técnicos de nuestras Administraciones locales. Escepticismo referido tanto a la conveniencia de una reforma planteada en esos términos (sus concretas orientaciones), como en lo que tenía que ver con su encaje constitucional (es decir, con sus posibilidades de ser aceptable en términos jurídicos), pero en general nadie discutía ni la necesidad de reformas ni la importancia de que, si éstas se acometían finalmente, fueran ambiciosas y no meros parches. Nada de ello han satisfecho el proceso de reforma seguido y el texto finalmente aprobado. La reforma, incluso en su formulación más suave, tras constatarse que tampoco las propias administraciones implicadas (las locales) o las Comunidades Autónomas mostraban el más mínimo entusiasmo, recibió también las severas críticas ya referidas del Consejo de Estado.

De manera que en la norma finalmente aprobada han desaparecido algunas de las líneas de reforma inicialmente presentadas con más fuerza, tales como la forzosa desaparición masiva de entidades locales menores o de entidades locales de tamaño superior al municipio e inferior a la provincia de tipo colaborativo o asociativo; el establecimiento de procesos de fusión forzosa de los municipios más pequeños y con problemas para gestionar correctamente ciertos servicios; e incluso la previsión de que las Diputaciones provinciales pudieran a partir de la constatación de la ineficiencia en la prestación de ciertos servicios (medida a través de un difuso "coste estándar") asumir directamente de forma masiva e imperativa la gestión de muchos servicios públicos locales de municipios de menos de 20.000 habitantes. En la norma definitivamente aprobada todas estas propuestas iniciales han dejado un rastro evidente, pero en las soluciones finalmente adoptadas hay más de voluntariedad y menos de coactividad, por lo que muchas de ellas aparecen como ideas y principios a los que tender pero ya ayunas, en la mayor parte de los supuestos (aunque no en todos), de los mecanismos que permitían su imposición imperativa por parte del Gobierno con los que quedaban mucho más respaldadas en los primeros borradores².

2 Así, por ejemplo, el nuevo artículo 13.3 de la LRBRL tal y como queda regulado por el texto aprobado por la LRSAL se limita a superponer a la competencia autonómica en materia de fusiones de municipios una acción del Estado, que, atendiendo a "criterios geográficos, sociales, económicos y culturales", se basará únicamente en el establecimiento de "medidas que tiendan a fomentar la fusión de municipios con el fin de mejorar la capacidad de gestión de los asuntos públicos locales". Medidas que pasan esencialmente por el incremento de su financiación, la preferencia en la asignación de planes de cooperación local o de subvenciones, o la dispensa en la prestación de nuevos 
Sin embargo, no por ello deja de ser verdad que la orientación y principios últimos de la reforma, por mucho que puedan haber quedado diluidas sus consecuencias, no han cambiado tanto y que, aunque sólo se aprecien en el texto finalmente aprobado algunos restos de esa pretensión de forzar ciertos cambios, el esquema último de régimen local que moldea la norma no es tan diferente, al menos, en los principios que lo inspiran ${ }^{3}$. Resulta por ello esencial prestarle atención teniendo en mente de dónde vienen algunas de las propuestas para poder atender mejor las ideas inspiradoras de todo este proceso, por mucho que hayan quedado en algunos casos muy atenuadas.

Este proceso de transformación se enmarca, por otro lado, y como es sabido, en la necesidad de acometer reformas de calado en la Administración española en sus diferentes niveles. Un diagnóstico que además no es sólo interno o político sino que viene también desde fuera, por ejemplo en forma de condicionalidad por los fondos que los diversos mecanismos de rescate bancario han puesto a disposición, en forma de "crédito muy ventajoso", de España para afrontar la reestructuración de algunas entidades financieras ${ }^{4}$. Obligaciones que incluso son jurídicas y han sido contraídas con Europa y constitucionalmente integradas en nuestro ordenamiento jurídico por la vía de la reforma del art. 135 de la Constitución, al menos en lo referido a la necesidad de ahorro -obviamente, no en cuanto a cómo conseguirlo o en cómo lograr mejoras de eficiencia, donde hay un margen político y de Derecho interno evidente-. Es en este contexto en el que se enmarcan los trabajos del INAP que han dado lugar a esta reforma local, junto a otros esfuerzos - de resultados también magros hasta la fecha- como los acometidos por la CORA (Comisión para la Reforma Administrativa5), que se ha limitado hasta la fecha a proponer reordenaciones menores en la gestión interna de la Administración del Estado y a difundir informes sobre la conveniencia de evitar "duplicidades" que siempre van en la línea de pedir la eliminación de entes autonómicos caso de que se entienda que existe una de ellas.

servicios obligatorios como consecuencia del aumento poblacional (medidas concretadas en el art. 13.4 que, por cierto, tampoco son de una especial generosidad, lo que puede convertir el mecanismo en poco empleado). En esta misma línea, el definitivo contenido del art. 26.2 en la nueva redacción establece que la prestación de ciertos servicios en municipios de menos de 20.000 habitantes será coordinada por las Diputaciones provinciales, pero que "para coordinar la citada prestación de servicios la Diputación propondrá, con la conformidad de los municipios afectados, al Ministerio de Hacienda y Administraciones Públicas la forma de prestación, consistente en la prestación directa por la Diputación o la implantación de fórmulas de gestión compartida a través de consorcios, mancomunidades u otras fórmulas". Desde el momento en que la conformidad de los municipios afectados es necesaria queda rebajada enormemente la voluntad de imponer cierto modelo que se atisbaba en los primeros borradores. Dos de las medidas estrella pues, del modelo inicial, basado en la fusión obligatoria y reducción de competencias, que pasarían a las Diputaciones, quedan, como se ve, enormemente desdibujadas, con lo que el modelo en sí acaba viniéndose abajo. Por su parte, la DT $1^{\text {a } ~ " s a l v a ” ~ f i n a l m e n t e ~ l a s ~ m a n c o m u n i d a d e s ~ s i e m p r e ~ y ~ c u a n d o ~ c u m p l a n ~ e l ~ r e ́ g i m e n ~ l e g a l ~ y a ~ v i g e n t e ~(a r t . ~} 44$ LBRL), mientras que en materia de consorcios la DA 9 a prohíbe la constitución de los mismos mientras un municipio se encuentre inmerso en un plan de ajuste y obliga a liquidar los que no estén en situación de equilibrio financiero, a la vez que introduce por medio de la DF $2^{\text {a }}$ una DA $20^{\mathrm{a}}$ a la Ley 30/1992, de Régimen Jurídico de las Administraciones Públicas y del Procedimiento Administrativo Común, con nuevo régimen jurídico para los mismos al que deberán adaptar paulatinamente sus estatutos.

3 Así, por ejemplo, el ya mencionado artículo 26.2 de la norma local básica según la redacción dada por la LRSAL sigue estableciendo, si bien ya modulado por esa idea de acuerdo, un sistema de prestación de ciertos servicios que claramente pretende ir llevando, aunque ya no sea exactamente de manera coactiva, a las Diputaciones provinciales la prestación de los mismos para aquellos municipios que no logren acreditar que sus “costes efectivos" de prestación son menores que los que garantiza la correspondiente Diputación provincial (u órgano equivalente), lo que permite por medio de medidas indirectas, entre las que puede estar el mismo ahogo financiero, ir recentralizando provincialmente estos servicios; o el ya referido artículo 13, que si bien en la redacción dada por la LRSAL renuncia a fusiones forzosas como ya se ha señalado, también dificulta enormemente la creación de nuevos municipios (y la imposibilita para entidades con menos de 5.000 habitantes); y las normas respecto de figuras de tipo asociativo que se han demostrado muy útiles en ocasiones como las mancomunidades o de mecanismos de participación de base y de acercamiento a los ciudadanos como las entidades locales menores, aunque no fuercen necesariamente a la disolución de las mismas, siguen manifestando una clara hostilidad (DT $4^{\mathrm{a}}$, DT 11 ${ }^{\mathrm{a}} \ldots$ ), al igual que ocurre con los consorcios y figuras afines.

4 El Memorandum of Understanding (MOU) o Memorando de Entendimiento sobre condiciones de Política Sectorial Financiera, hecho en Bruselas y Madrid el 23 de julio de 2012 (así como el correlativo Acuerdo Marco de Asistencia Financiera, hecho en Madrid y Luxemburgo el 24 de julio de 2012) donde se detallan las condiciones establecidas, y a las que el Reino de España se obliga en correspondencia a la ayuda financiera recibida, fue publicado por el BOE de 10 de diciembre de 2012. Aunque los compromisos adquiridos por España en virtud del mismo se refieren esencialmente a la reforma y estabilización del sistema financiero, es evidente que este contexto tiene mucho peso, como no ocultan sus promotores, en la decisión de acometer una reforma de las Administraciones públicas españolas para hacerlas, como señala la ley 27/2013, más “sostenibles". En este sentido, por ejemplo, Arenilla Sáez (2014: 18-19), como uno de los promotores del cambio legal que ha trabajado desde el INAP en la orientación y primeros borradores, no oculta la importancia de este factor en el proceso decisorio que lleva a la reforma, algo que también aparece en la propia exposición de motivos de la propia ley. Véase también Medina Guerrero (2014: 29-32). Para una explicación general de cómo ha cambiado el marco europeo y constitucional en nuestro Derecho público a la luz de la crisis y qué mecanismos de control han aparecido, uno de los cuales es el señalado, Embid Irujo (2012 y 2014) y también el trabajo de Menéndez (2014).

5 La tradición de crear comisiones de reforma administrativa, como es sabido, no es nueva (Jordana de Pozas, 1956), pero el esfuerzo de la CORA ha sido presentado como muy ambicioso. Sin embargo, como se deduce de una consulta crítica de su extenso informe en la Red (véase la referencia al mismo en el listado bibliográfico final), más allá de un ingente acopio de información y de algunas propuestas de racionalización de cierto interés en materia de contratación aprovechando las actuales posibilidades tecnológicas que permiten crear ciertas sinergias, por ejemplo (Cea Alaya, 2014), lo cierto es que las medidas parecen más voluntaristas muchas veces, y excesivamente centradas en convencer a otras Administraciones públicas (las autonómicas) respecto de la conveniencia de realizar modificaciones y transformaciones antes que en analizar las posibilidades de reforma y ahorro internas en la Administración del Estado (Boix Palop, 2013b). 
La valoración general sobre la reforma administrativa que de este proceso se deduce es, por ello, más bien pobre en sus contenidos y ambiciones, poco original y recentralizadora sin más en cuanto a su orientación política y por todo ello escasamente satisfactoria desde la perspectiva tanto del ahorro como de la eficiencia, que exigirían un análisis más matizado y fundamentado, por un lado, así como intervenciones con más contenido, por otro. Señala Muñoz Machado (2013) que, en este contexto, y ante la necesidad de lograr un ahorro de 8.000 millones de euros en gestión administrativa el expediente más fácil, constatada la nula voluntad de la Administración del Estado de autorrecetarse una cura de adelgazamiento que de verdad sea digna de ese nombre y las enormes dificultades jurídicas y políticas de ordenar una recentralización orgánica y funcional a las Comunidades Autónomas una vez ya se ha concretado la financiera y presupuestaria (con todo lo que ello ha supuesto, reforma constitucional incluida) a partir de mecanismos de legislación ordinaria, es reformar el régimen local, más intervenible. Cuestión distinta es que sea tan fácil obtener el mencionado ahorro, a la hora de la verdad (o siquiera una fracción del mismo) con la misma sencillez con la que se deciden y aprueban este tipo de reformas ${ }^{6}$.

Parece, pues, que, en definitiva, el origen de la reforma no es tanto una evaluación particularmente negativa respecto del funcionamiento de nuestros órganos locales ${ }^{7}$ ni, como por otra parte es una evidencia contable, porque sea particularmente grave la situación de sus cuentas públicas en su conjunto (es más, se trata de las Administraciones públicas con menos deuda y de las únicas que no incurren en déficit público en la actualidad, como recuerda respecto de su endeudamiento acumulado Carbonell Porras, 2013: 29-30), como los datos oficiales publicados por el Ministerio de Hacienda y Administraciones Públicas para el cierre del presupuesto de 2013 confirman $^{8}$, sino simplemente porque es el expediente jurídicamente más sencillo de afrontar. Probablemente no pocos de los problemas de la reforma tienen que ver con este planteamiento de partida: pensar que lo jurídicamente fácil, por el mero hecho de serlo, pueda serlo también social y políticamente y, lo que es peor, entender que el camino legislativa y políticamente más sencillo es, a su vez, el que ha de ser recorrido con independencia de que, haya más o menos dificultades, lo esencial debiera ser dónde se quiera llegar.

La reforma aprobada del régimen local, con estos defectos de partida, es además reflejo de algunas de las limitaciones constitucionales del encuadramiento jurídico de nuestras Administraciones locales. Así que aprovechando la coyuntura vale la pena hacer el esfuerzo de tratar de identificar las líneas generales que nos indican el sentido y objetivos de la reforma para, a continuación, intentar valorar la conveniencia de esas orientaciones y, sobre todo, las evidentes incoherencias que plantean si las contrastamos con la regulación que la Constitución española contiene en lo que se refiere a la autonomía local y al reparto competencial sobre el régimen local entre Estado y Comunidades Autónomas. $\mathrm{O}$, al menos, las incoherencias y contradicciones que, por mucho que quizás ahora no parezcan tan graves en un contexto donde la comprensión de nuestro Derecho público se ha vuelto con carácter general más centralista y limitadora respecto de la idea y extensión de lo que es cualquier autonomía institucional, sí lo habrían sido con la interpretación constitucional dominante hace un par de décadas, más generosa con el entendimiento de lo que debía ser la autonomía local o con las posibilidades de acción competencial de las Comunidades Autónomas.

La LRSAL, más allá de que se haya ido dulcificando a medida que los borradores se iban sucediendo y las propuestas no concitaban sino un rechazo muy generalizado en el mundo local, entre casi todos los especialistas

6 En este sentido, también, Muñoz Machado (2013). Respecto de la cifra de 8.000 millones de euros, montante total al parecer exigido desde la Unión Europea, lo cierto es que las medidas, borrador tras borrador, proyecto a proyecto, han pasado de ser explicadas por sus promotores como supuestas generadoras de un ahorro anual en esos umbrales a ser luego presentadas como productoras de estas mismas economías pero bianuales, para a continuación pasar los manidos 8.000 millones a ser el ahorro previsto para todo el período 2013 2016 y finalmente, a estas alturas, y por lo que se ha explicado en el momento de aprobar la norma, el ahorro al que se aspira a llegar durantelos años 2014-2019, pero ya no sólo con la reforma local sino con todos los cambios en nuestra organización administrativa local, incluyendo medidas de control presupuestario previas a la reforma local que estudiamos. Como se deduce fácilmente, una memoria económica seria ha brillado por su ausencia desde el primer momento, en lo que sigue siendo una práctica tristemente habitual pero particularmente espectacular en lo que se refiere a la aprobación de una ley que se ha demorado casi dos años y donde, precisamente, el acento reformista se ha puesto desde un primer momento en el supuesto ahorro económico que estaba destinada a generar.

7 Es curioso que ello sea así y sea además llevado a cabo sin un estudio mínimo de las experiencias de cambio y transformación llevadas a cabo en otros países en un momento en que habían proliferado obras muy completas documentando estos procesos en nuestro entorno comparado, como las coordinadas por Moreno Molina (2012) con experiencias en numerosos países de nuestro entorno, Velasco Caballero (2010) con una particular atención a la manera de resolver estas reformas en países con estructuras de tipo federal, Cosculluela Montaner y Carbonell Porras (2011) en referencia a la articulación de los mismos con las recientes reformas estatutarias y con interesantes miradas, también, al exterior, o, incluso, desde perspectivas no jurídicas, con trabajos como el de Lago Peñas y Martínez Vázquez (2013) sobre las dimensiones y estructuras apropiadas para el gobierno local desde una perspectiva más económica y política.

8 Los municipios españoles han cerrado 2013 no sólo siendo las únicas Administraciones públicas en no presentar déficit (a diferencia de lo que ocurre tanto con las Comunidades Autónomas como, sobre todo, con la Administración del Estado y la Seguridad Social, que presentan desequilibrios inquietantes y en el caso de la Administración del Estado ya por sí sola muy por encima de los límites máximos marcados por las normas tanto europeas como españolas), sino que globalmente han logrado un superávit del o'4\% en relación al PIB (los datos oficiales de cierre de ejercicio y demás información sobre la situación financiera de las Administraciones locales están disponibles en la web del Ministerio en http://www.minhap.gob.es/ca-ES/Areas\%20Tematicas/Administracion\%20Electronica/OVEELL/Paginas/DatosFinanciacionEL.aspx -consulta 1 de mayo de 2014). 
(véase, por ejemplo, la muy crítica evaluación que realizó Velasco Caballero, 2013) e incluso, como ya se ha comentado, en órganos consultivos no demasiado beligerantes -por lo común- con los proyectos de reforma que le remiten los sucesivos gobiernos como el Consejo de Estado, sigue respondiendo a tres ideas esenciales que, por mucho que suavizadas, todavía son reconocibles en el texto final de la ley. A partir de ellas vamos a vehicular estas reflexiones, dando ejemplos sobre cómo se van plasmando en el texto, porque de este modo es posible entender mejor la panorámica general tanto de lo que pretendía lograr la reforma como de las que es previsible que sean sus efectivas posibilidades de éxito cuando haya de ser aplicada.

Así, de una parte, la nueva ley refleja un entendimiento muy poco ambicioso de la autonomía local, por no decir que es francamente hostil a su misma idea. Toda la reforma transmite desconfianza hacia los ayuntamientos, a los que se intenta limitar y constreñir en su actuación por muy diversas vías, así como predeterminar todo lo posible respecto de cómo han de organizarse hasta umbrales insospechados y, por ello, difícilmente conciliables con lo que habitualmente hemos entendido por autonomía local en España hasta hace muy poco.

De otra, la reforma se asienta en la consideración de que la organización del régimen local es cuestión que esencial, cuando no únicamente, concierne al Estado, sin que las Comunidades Autónomas tengan mucho más que decir, a efectos estructurales, sobre lo que sean los municipios, cómo deban organizarse y qué deban hacer más allá de ceñirse a concretar y desarrollar el esquema ordenador previamente diseñado por el Estado. La reforma planteada, a estos efectos, no sólo jibariza el régimen local español sino que lo desplaza hacia un control mucho más predeterminado por el Estado.

Por último, y a partir de la interposición de una institución tan peculiar en muchos de sus trazos (elección democrática indirecta ${ }^{9}$, inexistencia en la mitad del territorio estatal ${ }^{10}$, connotaciones centralistas evidentes, desubicación constitucional tras la aparición de las Comunidades Autónomas) como es la Diputación provincial, la reforma aspira también, de forma muy poco velada, a crear mercados de ámbito provincial para la prestación de muchos servicios públicos, pues éste y no otro es el efecto de desplazar las decisiones de gestión de los entes locales de ámbito municipal a los entes locales provinciales.

Todo ello, además, se realiza a partir de un entendimiento de la capacidad que tiene el Estado para legislar y supraordenar, ya sea para limitar la idea de autonomía local, ya para desplazar a las Comunidades Autónomas en el ejercicio de sus competencias, que se ha incrementado notablemente tras la reforma constitucional de agosto de 2011 que dio una nueva redacción al artículo 135, las normas de desarrollo asociadas a la misma en materia de estabilidad financiera" y muy especialmente, a partir de ahí, por la vía de un nuevo entendimiento de la competencia horizontal contenida en el artículo 149.1.14 $\mathrm{CE}$, sobre Hacienda general y deuda, que aparece convertido en una especie de vórtice que succiona todo lo que hay enrededor para acabar haciendo confluir todo en un mismo punto: el control del Estado y del Gobierno central sobre toda la acción pública y administrativa del país, que se entiende justificado constitucionalmente y competencialmente posible en cuanto se invoque la existencia de un riesgo de tipo financiero, por remoto o teórico que sea (como es el caso de la reforma local, de hecho, respecto de los municipios muy especialmente de los más pequeños, si atendemos a su nivel de endeudamiento, Carbonell Porras, 2013: 29-30).

Vamos a tratar de desarrollar estas cuestiones con algo más de detalle para quienes prefieran, llegados a este punto, ir más allá de esta valoración inicial y analizar con más profundidad cada uno de estos puntos.

\section{REFORMA DEL RÉGIMEN LOCAL Y DEBILIDAD DE LA GARANTÍA DE LA AUTONOMÍA MUNICIPAL}

El elemento estructural más importante de la reforma, y el que más consecuencias puede acabar teniendo a largo plazo para la estructura global de nuestro sistema de reparto territorial del poder desde una óptica constitucional, es su entendimiento de la autonomía local como una barrera más bien testimonial frente a las pretensiones del legislador ordinario de despojar de funciones y servicios a los municipios, así como a la hora de

9 Lo que supone un problema evidente pero que hasta la fecha el Derecho español no ha pretenddido solucionar, algo que es una apreciación ya muy compartida y que debería obligar a actuar en esa dirección (Almeida Cerreda, 2013: 40-41), máxime si se pretende fortalecer competencialmente a estas instituciones.

10 Como es obvio, que no existan Diputaciones provinciales no significa que no haya órganos equivalentes (desde las propias Comunidades Autónomas en las que son uniprovinciales a las instituciones de ámbito insular en los archipiélagos o las formas propias de los territorios forales) que vayan a encargarse de las mismas funciones que la reforma asigna a las Diputaciones provinciales. Pero vale la pena mencionar este aspecto a efectos de entender hasta qué punto la forma provincial de prestación de ciertos servicios y la necesidad de que exista una institución local de ese ámbito es constitucionalmente dudoso que sea ineluctable, como la propia inexistencia de Diputaciones provinciales en gran parte del territorio nacional pone de manifiesto en la práctica de forma patente (sobre esta cuestión, extensamente, Boix Palop, 2013a: 111-119).

11 Como es sabido, la más importante de estas normas es la Ley Orgánica 2/2012, de 27 de abril, de Estabilidad Presupuestaria y Sostenibilidad Financiera, publicada en el BOE de 30 de marzo de 2012 y que, justamente, da continuidad y desarrolla los nuevos contenidos del artículo 135 de la Constitución. 
poder establecer espacios de autonomía organizativa efectiva interna dignos de ese nombre (comparables, por ejemplo, a los que son los propios de las Comunidades Autónomas y que, en este punto, el Tribunal Constitucional, al menos hasta la fecha, ha defendido siempre con bastante consistencia). Se trata de una nota que se infería claramente de las versiones previas al Anteproyecto, que aun minimizado enhebraba el entendimiento de lo que era posible determinar que contenía el ALRSAL y que, incluso tras el proceso de poda a que ha sido sometido el proyecto final para acomodarlo a los planteamientos del Consejo de Estado, podía verse aún en el proyecto de ley (PLRSAL) finalmente presentado por el gobierno por lo que a la postre ha acabado también reflejada en la ley finalmente aprobada. Hay una evidente línea de continuidad entre considerar que el legislador puede eliminar muchas competencias hasta ahora propias de los entes locales ( $y$ algunas de ellas, de importancia no menor, como las que se refieren a su participación en relevantes parcelas de la gestión de los servicios sociales, sanitarios y educativos) y llegar a pensar que incluso se puedan predeterminar procedimientos para forzar a su concentración en entes territorialmente superiores (algo que, por lo demás, se ha mantenido finalmente para algunos casos excepcionales, como es el caso del art. 116 bis en su redacción LRSAL para casos de incumplimientos del plan de estabilidad presupuestaria, que permite la retirada de competencias ${ }^{12}$ ), con la posibilidad incluso de poder llegar a tener entes locales sin apenas competencias efectivas para la gestión de sus intereses propios. Aunque de los primeros textos a la ley aprobada la letra haya cambiado, la música en este punto no ha dejado de ser la misma. Una música en la que, aunque se trate de una cuestión testimonial, la idea de autonomía local no es mencionada en la Exposición de Motivos más que en una sola ocasión en realidad más como apoyo argumental para justificar la competencia estatal para legislar la cuestión que para cualquier otra cosa (lo ha resaltado también Jiménez Asensio, 2013).

En este sentido, hay que señalar que existen dos planos diferenciados para la reflexión que hemos de distinguir. En primer lugar, la efectiva existencia de posibilidades en la Constitución que, con base en la autonomía local, puedan limitar al legislador en este punto. En segundo término, y con independencia de lo que podamos concluir respecto del primer punto, habrá que analizar qué entendimiento de la autonomía local (más bien pobre, puede anticiparse ya) contiene el modelo efectivamente elegido por el parlamento español con la aprobación de la LRSAL.

Resulta por ello necesario plantear, en primer lugar y a la luz de este proyecto de reforma, cuál pueda ser la sustantividad de la idea de autonomía local en la Constitución desde un punto de vista jurídico. Esto es, hasta qué punto constituye una garantía efectiva frente al poder legislativo o si, por el contrario, estamos en un terreno donde todos los contenidos de la misma serían totalmente (o casi totalmente) disponibles para el legislador. En este sentido, no puede negarse que el reconocimiento constitucional de la misma es ciertamente débil. Aunque el artículo 137 CE establece esta autonomía para la gestión de los intereses que le son propios en idénticos términos para las Comunidades Autónomas, provincias y municipios resulta evidente que no es la misma la situación en cada uno de esos casos. Las Comunidades Autónomas tienen después un anclaje competencial claro a partir de las listas de los artículos 148 y sobre todo 149 de la Constitución, que marca el límite máximo de competencias que pueden asumir sus Estatutos de Autonomía y establece, así, indirectamente, un ámbito posible de acción autonómica protegida claramente imbricado con el diseño constitucional. Por el contrario, los municipios han de conformarse con una apelación muy genérica en el artículo $140 \mathrm{CE}$, que si bien vuelve a reconocer su autonomía para la gestión de sus intereses (a diferencia de lo que ocurre luego con las provincias, por ejemplo), se limita a establecer unas mínimas pautas organizativas y a mencionar, eso sí, que "su gobierno y administración corresponde a sus respectivos Ayuntamientos" pero sin mayores concreciones y sin establecer, en ningún caso, un listado de competencias o de áreas que se correspondan con ese ámbito de "gestión de sus respectivos intereses" que pueda ser entendido como expresamente integrado en el diseño constitucional. Serán los intérpretes de la Constitución, y por ello en primer término el propio legislador y en última instancia el Tribunal Constitucional, los que hayan de definir y en su caso proteger el concreto contenido de la autonomía local constitucionalmente garantizada. En este punto, principios jurídicos como el de subsidiaridad (que en el fondo es un trasunto de principios constitucionales como el de democracia y participación en su intersección con la eficiencia, Boix Palop, 2013a: 38-42, que la Unión Europea tiene plenamente incorporados y concretados respecto del régimen local, Medina Guerrero, 2014: 2831), al haber sido plasmados y desarrollados por el Derecho de la Unión Europea, podrían servir para dotar de

12 En adición a lo que ya prevé en estos casos, en materia de intervención financiera, el artículo 21 de la ya mencionada Ley Orgánica 2/2012, de 27 de abril, de Estabilidad Presupuestaria y Sostenibilidad Financiera, la reforma local, por medio del mencionado nuevo art. 116 bis prevé que el plan económico-financiero aprobado pueda intervenir en las competencias municipales y su forma de prestación, pudiendo desde suprimir directamente todas las competencias que el municipio esté ejerciendo y que sean "distintas de las propias" (esto es, las conocidas popularmente como "competencias impropias" del art. 7.4 LBRL en su nueva redacción), así como todas las que se estén ejerciendo por delegación (arts. 7.1 y 7.3 en relación con las nuevas reglas del art. 27 sobre cómo haya de operar ésta y con qué controles) hasta determinar modelos de "gestión integrada o coordinada de los servicios obligatorios que presta la Entidad Local para reducir sus costes" en los que tendría una importante participación la Diputación provincial (art. 116 bis 3). 
cierta sustantividad jurídica a la autonomía local, pero ello requiere de una tradición de análisis constitucional más principalista y con un Tribunal constitucional más interventor (a la manera alemana, por ejemplo) del que, como es manifiesto (sea para bien, sea para mal) tenemos en España, donde el ámbito de libre determinación del legislador es en la práctica de nuestros particulares checks and balances mucho mayor ${ }^{13}$.

Como es evidente, para acometer esta tarea existen instrumentos jurídicos interpretativos que pueden ayudar a densificar lo que constitucionalmente sea la autonomía local como barrera de defensa de esa esfera de actos propios. Por una parte, contamos con aquello que ha ido señalando el Tribunal Constitucional a lo largo de estos años. Sin embargo, su jurisprudencia tampoco ayuda en exceso, pues más allá de reconocer, como no puede ser menos, que esta autonomía "es uno de los principios estructurales básicos de nuestra Constitución”, no la completa ni delimita de forma materialmente sustancial y, además, desde un primer momento la situó en un nivel diferente a la autonomía de las Comunidades Autónomas, que "gozan de una autonomía cualitativamente superior a la administrativa que corresponde a los entes locales" (STC 25/1981), del mismo modo que tampoco la autonomía, que en todo caso "resulta claro que (... ) hace referencia a un poder limitado" (STC 4/1981), estaría a su vez al mismo nivel que la soberanía.

Algo más de concreción encontramos, pero no demasiada tampoco, en las muchas sentencias que han repetido la idea de que la autonomía local es un "derecho de la comunidad local a participar a través de órganos propios en el gobierno y administración de cuantos asuntos le atañen, graduándose la intensidad de esta participación en función de la relación existente entre los intereses locales y supralocales en tales asuntos y materias" (STC 32/1981), idea luego repetida en innumerables sentencias). En definitiva, que el Tribunal Constitucional ha acabado dejando que el legislador defina con mucha libertad cuáles hayan de ser los intereses de los entes locales, señalando que "más allá de este límite de contenido mínimo que protege la garantía institucional, la autonomía local es un concepto jurídico de contenido legal, que permite, por tanto, configuraciones legales diversas, válidas en cuanto respeten aquella garantía institucional" (STC 170/1989), idea también repetida después en muchas sentencias posteriores). Aparece pues aquí la idea de que el límite vendría definido por esa "garantía institucional" que recoge la Constitución, que impediría alterar o regular la institución de forma que pudiera quedar irreconocible pero poco más y, sobre todo, nada concreto más. Como dice la propia STC 170/1989, "sería contrario a la autonomía municipal una participación inexistente o meramente simbólica que hiciera inviable la participación institucional de los Ayuntamientos", lo que por ser una obviedad de mínimos no ayuda nada, la verdad, a avanzar. Por mucho que haya habido intentos de dotar de una mayor sustantividad a la garantía, de argumentar su mayor concreción (en particular, véase la síntesis que hace Parejo Alfonso, 2011: 145-154) la conclusión no deja de ser decepcionante si lo que andamos buscando es una efectiva barrera, mínimamente densa, a la libertad de conformación del legislador ${ }^{14}$. El actual proceso de reforma es un buen ejemplo de ello, de hecho, por cuanto parece que los motivos del repliegue final del legislador español habrían sido más bien de oportunidad y políticos (la reforma no suscitaba acuerdos) que una efectiva falta de convicción de sus promotores en la constitucionalidad de la misma.

Cabe, eso sí, indagar en instrumentos normativos suscritos por España como la Carta Europea de Autonomía Local de 1985 para rellenar de contenido esa garantía institucional, pero tampoco es sencillo extraer de ahí mandatos que vayan mucho más allá aunque algunas de sus notas sí pueden plantear puntuales problemas interpretativos de cierta entidad, caso de que sus planteamientos sean tomados en serio, respecto de la LRSAL (Parejo Alfonso, 2011: 159-161). De hecho, y aunque el artículo 3 de la misma no va mucho más allá, y entiende por autonomía local el "derecho y la capacidad efectiva para las entidades locales de regular y administrar, en el marco de la Ley, bajo su propia responsabilidad y en beneficio de su población, una parte importante de los asuntos públicos", lo que no es mucho más de lo que suele decir el Tribunal Constitucional, en el art. 4 sí encontramos algunas obligaciones con más sustancia y concreción.

Así, en materia de las efectivas competencias que deban ser encomendadas a los municipios, sí resulta de gran interés lo que señala la carta, esencialmente respecto del régimen de ejercicio de las competencias y del esquema para el proceso de asignación de sus concretas competencias locales (Parejo Alfonso, 2011: 167).

13 En este sentido, por ejemplo, puede ser interesante remitir a los estudios que, más allá de la efectiva concreción que pueda suponer la idea de subsidiariedad y su plasmación y concreción respecto de lo local en el Derecho europeo (Medina Guerrero, 2014: 38-40), se refieren a la delimitación de "lo local" desde otras perspectivas, como politológicas (y de tamaño, estudio clásico de Alesina y Spolaore, 2003) o económicas (a las que ya hemos hecho referencia al mencionar el trabajo colectivo dirigido por Lago Peñas y Martínez Vázquez, 2013). Ocurre, sin embargo, que estas perspectivas, por muy interesantes que puedan ser para adoptar decisiones de oportunidad tienen escasa capacidad para condicionar, en un modelo como el español, las decisiones desde un plano jurídico, de constitucionalidad.

14 Tiene razón Baño León (1988: 165-173) en que tiene poco sentido distinguir entre derechos fundamentales y garantías institucionales a efectos de protección. En un contexto de normatividad plena de la Constitución lo importante es, en su caso, identificar exactamente hasta dónde llegan las previsiones constitucionales. Ocurre, sin embargo, que en materia de autonomía local (o de cualquier otra de las garantías institucionales que suelen ser predicadas) ello obliga a una evaluación donde es cierto que en ausencia de concreción constitucional el grado de maleabilidad concedido al legislador, al menos en un modelo de revisión constitucional como el español, tiende a ser mayor. 
Y en este sentido sí ha de señalarse que el Estado español estaría vinculado por normas como el art. 4.1 de la Carta, que obliga a que las competencias vengan fijadas en la Constitución o en la ley, pero que también permite que existan atribuciones adicionales, lo que va contra uno de los principios básicos de la reforma española en sus planteamientos iniciales, que hay quien considera que subsiste a la hora de interpretar las posibilidades de atribución de más competencias por parte de las Comunidades Autónomas, pues inicialmente aspiraba a limitar enormemente el ejercicio de cualquier competencia que no hubiera sido expresamente atribuida por ley básica estatal (con excepción de algunas posibilidades de atribución autonómica que, además, han aparecido finalmente en el texto de ley tras su introducción en el PLRSAL pero que ni siquiera estaban en el ALRSAL, que era si cabe más restrictivo $)^{15}$. Idea que, además, refuerza enormemente el art. 4.2 cuando señala que las entidades locales “tienen, dentro del ámbito de la Ley, libertad plena para ejercer su iniciativa en toda materia que no esté excluida de su competencia o atribuida a otra autoridad", lo que directamente avala la interpretación extensiva de la vieja cláusula general de competencia del art. 28 LBRL que, en cambio, el proyecto de reforma local ha derogado por ser una de sus explícitas orientaciones regulativas la limitación de las posibilidades de expansión de lo local a partir de la decisión de los propios ayuntamientos. La contradicción parece evidente, a poco contenido normativo efectivo que concedamos a la Carta y sobre todo si creemos que no sólo integra el ordenamiento jurídico español sino que es un elemento esencial para interpretar en qué términos constitucionales deba entenderse el sentido de la garantía institucional de la autonomía local.

Adicionalmente, parece que el art. 4.3 de la Carta, al establecer una clara expresión del principio de subsidiaridad, está no sólo recogiendo el sentir mayoritario en este sentido desde el punto de vista de la conveniencia sino también fijando un determinado mandato que, por ejemplo, es dudoso que se cumpla si por motivos exclusivamente financieros se sustrae la competencia, como todavía permite hacer excepcionalmente la ley en casos de incumplimientos a las obligaciones de déficit público, al municipio para residenciarla en un nivel superior (recuérdense de nuevo las posibilidades ya reseñadas que el nuevo art. 116 bis 2 proporciona en este sentido, más allá de lo que ya en su momento preveía la LO 2/2012 de Estabilidad Presupuestaria). Paradójicamente, podría argumentarse que un mandato tan criticado como lo fue el que tenía el ALRSAL, cuando establecía además de estos mecanismos (coactivos) otros que también reubicaban competencias en niveles superiores pero por consideraciones de eficiencia (a partir de la idea de coste estándar luego desechada), era en el fondo más respetuoso con la Carta que el contenido finalmente aprobado en estos términos, que lo ordena como un castigo o consecuencia por el incumplimiento de obligaciones en materia de déficit de un modo muy semejante a una avocación ${ }^{16}$, y además con independencia de que esos desvíos tengan o no que ver con la eficiencia en la

15 Se trata de un debate esencial, por cuanto, con independencia de las competencias propias (art. 7.1 LBRL) atribuidas por la ley o delegadas a partir de los mecanismos en ella previstos y que se concretan en las previsiones de los artículos 25 , que lista las competencias propias; 26 , los servicios obligatorios que han de prestarse necesariamente por los municipios; y 27, donde se establecen los mecanismos de delegación de competencias por parte tanto del Estado como de las Comunidades Autónomas (que, como ya se ha dicho, son más generosos y abiertos que el inicial numerus clausus que la reforma pretendía), cabe plantear que las Comunidades Autónomas no tienen por qué estar vinculadas al listado del artículo 25 a la hora de decidir si ampliar el ámbito competencial de los municipios que se encuentran en sus respectivos territorios. El precepto les vincularía, como ha sido el caso hasta la fecha, para obligarles a ceder en esos casos la competencia. Ahora bien, dentro de su ámbito de dominio competencial, tanto en sus leyes de régimen local como en la legislación sectorial no debe entenderse que haya obstáculo legal alguno para que las normas autonómicas atribuyan más competencias a los entes locales. Competencias que no serían delegadas, y no deberían por esta razón seguir las pautas del art. 27 LBRL, sino propias a todos los efectos. A favor de esta interpretación, que es la mantenida con total normalidad hasta la fecha, juega el entendimiento pacífico de esta cuestión durante la vigencia de la LBRL en su versión del 1985 y así ha sido defendido, señeramente, por Velasco Caballero. En contra, además de la voluntad de los borradores legislativos y la tramitación del proyecto, aparecen las explícitas regulaciones en materias de competencia autonómica (educación, sanidad, servicios sociales...) que por vía de disposiciones adicionales y transitorias (DA $15^{\mathrm{a}}$, DT $1^{\mathrm{a}}$ y DT $2^{\mathrm{a}}$ para servicios educativos, sanitarios o de prestaciones sociales), plantean directamente un modelo de "devolución” competencial desde los ayuntamientos a las Comunidades Autónomas (como señala Zafra Víctor (2014), ello es realizado con diferente intensidad según los casos y "mientras que en lo relativo a sanidad y educación la Ley elimina las materias e impone las competencias a las comunidades autónomas, en los servicios sociales señala una materia con tal grado de precisión que difícilmente el legislador autonómico podrá entenderla como un mínimo”). La práctica, y la legislación autonómica ya en desarrollo están demostrando que tanto entes locales como Comunidades Autónomas siguen confiando en su capacidad de determinación de competencias propias más allá las previsiones de la norma estatal. Ello es así tanto en Comunidades Autónomas con un régimen local propio potente y estatutario como el País Vasco, Cataluña, Andalucía como en otras que no han incorporado a su Estatuto de Autonomía demasiadas previsiones al respecto. Pero como ello no significa que no tengan y puedan ejercer la competencia, lo están haciendo a efectos blindar el reparto competencial previo a la ley. Así, el parlamento de Galicia está en estos momentos tramitando un proyecto de ley presentado por el gobierno para reapoderar por medio de la norma autonómica a los municipios con las competencias que la norma básica estatal parece que pretende hacer desaparecer, mientras que el Gobierno de Castilla y León ha hecho lo propio por medio de su Decreto-ley $1 / 2014$, de 27 de marzo, de medidas urgentes para la garantía y continuidad de los servicios públicos en Castilla y León, derivado de la entrada en vigor de la Ley $27 / 2013$, de 27 de diciembre, de racionalización y sostenibilidad de la Administración Local. En idéntico sentido, en el momento de cerrar este trabajo, el gobierno andaluz ha anunciado, el día 20 de mayo de 2014, la aprobación para Andalucía de un Decreto-ley con idénticas intenciones que daría continuidad tanto a las previsiones estatutarias como a las atribuciones competenciales contenidas tanto en la ley de régimen local andaluza como en su legislación sectorial (norma finalmente aparecida en el Boletín Oficial de la Junta de Extremadura el día 28 de mayo de 2014: Decreto-ley 7/2014, de 20 de mayo, por el que se establecen medidas urgentes para la aplicación de la ley 27/2013, de 27 de diciembre, de racionalización y sostenibilidad de la Administración local).

16 La avocación sólo es posible en nuestro ordenamiento jurídico en casos de subordinación jerárquica o, fuera de ellos, cuando una 
prestación del servicio a escala local. Porque en el primer caso, al menos siempre y cuando entendiéramos que la nueva delimitación competencial, por rácana que fuera, era constitucionalmente posible y respetuosa de la autonomía local, aun considerada con poca generosidad, podría haber sido admisible, mientras que en el segundo se instrumenta un mecanismo de tutela que demuestra un claro carácter subordinado de la Administración local que es difícilmente compatible con la idea de autonomía expresada en la Carta.

A efectos de integrar la idea de garantía institucional, al menos si la queremos entender como jurídicamente dotada de significación que permita oponerse a ciertas regulaciones hechas por el legislador, y desde la perspectiva de que la misma cubre y protege la institución en la medida en que sea reconocible, cabe plantearse también, por ello, si el normal ejercicio de toda una serie de competencias y atribuciones desde 1986, desbordando el listado competencial de la LRBRL (las Ilamadas "competencias impropias", que no son sino demostración clara de la conveniencia de que los entes locales hagan más cosas incluso de las contenidas en la norma, pues su acción y esfera de intereses desbordaba manifiestamente la previsión legal, Almeida Cerreda, 2013: 9-12) no habría venido, de alguna manera, a dotar de unos perfiles concretos al ejercicio de la autonomía local que, quizás, no serían disponibles para el legislador. La propia reacción de la práctica totalidad de autoridades locales y sus instituciones representativas comunes dan buena prueba del alto impacto que la reforma, a su juicio, tenía en la manera en que estos entes vivían la autonomía local. ¿Puede entenderse por ello que esa idea de recognoscibilidad queda afectada por una reforma que limita seriamente facultades que no sólo estaban legalmente establecidas sino que se venían ejerciendo en la práctica de manera general y sin mayores problemas? ${ }^{17}$

El hecho de que el gobierno, tanto en sus iniciales borradores, como en el ALRSAL y como finalmente en el PLRSAL que a la postre se ha acabado traduciendo en el texto aprobado en sede legislativa, no hayan considerado problemática esta cuestión es buena prueba de la endeblez jurídica de la protección en sentido material que a la hora de la verdad otorga la construcción jurídica realizada en España a partir de la idea de "garantía institucional”, por mucho que supuestamente ésta se haya visto reforzada con la introducción del conflicto en defensa de la autonomía local en la LOTC a partir de la LO 7/1999 (Parejo Alfonso, 2001: 200-203). La existencia de vías procesales de defensa, aun con sus limitaciones, es esencial para poder vehicular conflictos, pero lo cierto es que en estos casos lo realmente esencial no es tanto el procedimiento como la conciencia de efectiva fuerza jurídica de la idea de garantía institucional que la comunidad jurídica y particularmente el Tribunal Constitucional acredite. No parece que en nuestro caso sea ésta excesiva (Velasco Caballero, 2014a: 85-86, por ejemplo, acaba optando por ello por contrastar la constitucionalidad de la norma con los mínimos funcionales o competenciales concretos a favor de la autonomía local que se pueden rastrear en la Constitución por permitir "un juicio de constitucionalidad más directo y asequible que el vaporoso juicio de "recognoscibilidad" constitucional que propicia la garantía institucional de la autonomía local”).

Estas insuficiencias quedan plasmadas en el dictamen del Consejo de Estado, que siendo cierto que realiza apelaciones a la autonomía local en ningún momento considera que haya una concreta quiebra normativa, y menos aún inspirada en la Carta o en la idea de una autonomía local vigorosamente instituida constitucionalmente como garantía institucional ${ }^{18}$, sino que realiza una valoración principial en que el problema deriva de una superposición de factores (coactividad; desplazamiento masivo a unos entes, las Diputaciones provinciales, de los que se

competencia propia se ha delegado en otro ente (art. 14 ley 30/1992). La regulación finalmente aprobada se parece mucho, sin embargo, a esta tradicional figura, incluso en lo que se refiere a las causas que podrían justiticarla (el art. 14.1 ley $30 / 1992$ habla de "circunstancias de índole técnica, económica, social, jurídica o territorial lo hagan conveniente”). De modo que la conclusión que se antoja respecto de la concepción que transmite esta regla en lo que se refiere a la posición de los entes locales es bastante obvia, quedando en un terreno parecido al de quienes están subordinados jerárquicamente o simplemente ejercen competencias en nombre de otro y sometidos a su mejor fiscalización.

17 Para un estudio del efectivo recorte competencial producido, Santamaría Pastor (2014: 139-149); Forcadell i Esteller (2014: 58-68); y más específicamente sobre la reducción de materias de necesaria competencia municipal y el traslado forzoso de algunas competencias llamadas “impropias”, Velasco Caballero (2014a: 91-103).

18 Véase, en su parte III a) 1, cómo, tras una torturada argumentación, acaba concluyendo respecto de la nueva delimitación competencial que "de conformidad con este planteamiento, no puede sin más afirmarse que la regulación en proyecto atente contra la garantía institucional de la autonomía local, por más que de ella resulte un marco competencial más estrecho que el que definía hasta ahora la LBRL. No cabe desconocer la importancia que para la configuración de las entidades locales tiene la definición de las competencias de los Municipios, trasunto de su autonomía y elemento caracterizador de su régimen jurídico, pero el mero hecho de que el haz de competencias que hasta ahora tenían reconocidas se vea reducido como consecuencia de la reforma proyectada no determina per se una afectación de la autonomía local de tal intensidad que pueda implicar una vulneración de la garantía institucional. Ahora bien, tal conclusión no ha de impedir que se advierta que el juego conjunto de los distintos preceptos que definen el nuevo modelo (en particular, los artículos 25 y 26 y disposiciones concordantes, así como el artículo 7.4 y la disposición transitoria novena, en lo que a las competencias impropias se refiere) da lugar a una considerable constricción de la autonomía de los Municipios cuyas consecuencias prácticas podrían quedar moduladas si se reconsiderasen algunos aspectos concretos de la regulación proyectada, que serán objeto de examen en los apartados siguientes de este dictamen”. Peculiar pauta jurídica de contraste de la corrección de una actuación legislativa ésta que requiere de poner en la balanza tantos y tantos elementos conjuntamente para poder juzgar si el resultado es global (pero no puntualmente, respecto de cada cuestión concreta) satisfactorio o no. Más que nada porque ese juicio, en condiciones normales, es sensato argumentar que es mejor que pertenezca al legislador. 
señala su falta de legitimación democrática directa, pero no tanto porque sea problemático el desplazamiento en sí como el hecho de a quién acaban allegándose las competencias; o la ausencia de una definición precisa del coste estándar que justificaba en el ALRSAL, más por problemas de seguridad jurídica que porque el Consejo de Estado entienda imposible que una mecanismo como éste pueda existir sin quiebra de la autonomía local). Puede concluirse, en general, que parece claro que la idea de garantía institucional requiere de un intérprete constitucional más intervencionista, sea este rasgo bueno o malo, que el Tribunal Constitucional español. No es extraño que las teorías en defensa de las posibilidades extraíbles de la idea de grantía institucional surgieran y tuvieran una evidente utilidad en un contexto diferente, como es el del Derecho público alemán en un momento de menor conciencia de normatividad de la Constitución (Baño León, 1988: 165-169) y, además, desarrollado posteriormente a partir de la labor de un Tribunal Constitucional que es mucho más dado a enmendar la plana al legislador y a extraer soluciones concretas de principios constitucionales que enmarcan mucho más la tarea del legislador de lo que es habitual en España. Pero no podemos perder de vista que precisamente por esta razón, la efectividad que podemos esperar de esta idea, en nuestro país, como defensa frente a las pretensiones del legislador es más bien escasa.

Por esta razón, la ley de reforma local refleja con crudeza, en el fondo, lo que no es sino la realidad constitucional española en materia de autonomía local: la posibilidad de un efectivo vaciamiento de contenido material de la garantía institucional de la autonomía local sin excesivas dificultades, caso de que el legislador así lo entienda. Ello permite que, incluso en su versión reformada, las medidas que se contienen en el texto que son problemáticas pero que es evidente que ni al gobierno ni a la mayor parte de la comunidad jurídica se lo parecen (en el sentido de que puedan ser anuladas por el Tribunal Constitucional) sean numerosas y formen parte, de hecho, de los contenidos más elementales de la reforma. Pero son problemáticas y cuestionables, muy probablemente, por consideraciones de oportunidad, por pretender un vaciamiento muy cuestionable de las efectivas esferas de actuación de los municipios, por liquidar en gran parte la efectiva capacidad de actuación autónoma de los municipios (con lo que ello supone desde muchos planos: subsidiariedad, control democrático, posibilidades de participación...) pero no porque jurídicamente no pueda el legislador democrático, en nuestro modelo constitucional, acometer una reforma de estas características.

Un legislador que ha optado decididamente por definir un ámbito para esa autonomía local que va a los límites mínimos constitucionalmente posibles, con un amplio abanico de medidas que jibarizan la efectiva (y hasta la fecha usual) acción de los entes locales:

- limitaciones competenciales en el nuevo listado del art. 25 LRBRL, donde desaparecen algunas competencias, significativas en no pocos casos, que venían siendo atribuidas a los entes locales ${ }^{19}$;

- eliminación de la idea de competencia implícita general o extensión a otros dominios de interés del régimen local (la derogación del artículo 28 LRBRL por la LRSAL es ciertamente significativa de lo que supone esta visión de una "autonomía local limitada" que se deduce de la voluntad del legislador ${ }^{20}$ );

- regulación muy limitativa de la gestión de competencias inicialmente llamadas "impropias" (ahora competencias otras a las legalmente atribuidas, según expresión de la Exposición de Motivos, véase cómo queda la redacción del art. 7.4 LBRL ${ }^{21}$ ) y sometida a mecanismos de control y autorización impropios de

19 Sobre el nuevo sistema de competencias locales y su génesis e intenciones, de nuevo, Arenilla Sáez (2014). Véase también la exposición que hacen de las efectivas transformaciones del régimen de competencias locales, esquematizadas de forma muy instructiva, Santamaría Pastor (2014: 141-143); y Forcadell i Esteller (2014: 59-69). También, de forma más analítica, Velasco Caballero (2014a: 88-104), entendiendo en general constitucional el modelo competencial resultante de reducción todos ellos, pues la autonomía local no sirve de efectivo valladar frente a estas pretensiones del legislador. Por otra parte, y como cada vez es más habitual que ocurra, se configura como inusitada fuente interpretativa del Derecho la figura de la "nota explicativa", en este caso la emitida por el Ministerio de Hacienda y Administraciones Públicas ("Nota explicativa de la reforma local”, http://www.minhap.gob.es/Documentacion/Publico/PortalVarios/Gestión\%20del\%2oPortal/ Nota\%20explicativa\%20de\%2ola\%20reforma\%2olocal.pdf, consulta 1 de mayo de 2014), donde se realiza un análisis con la idea de realizar una “clarificación de las competencias" que deja bien claro que los cambios en la enunciación de las competencias tienen siempre una vocación clara de restringir el alcance de las mismas. También la Federación Estatal de Municipios y Provincias, por su parte, ha emitido diversos documentos a través de su web en respuesta a consultas y preguntas donde se adhiere a la tesis de considerar que el nuevo art. 25.2 LRBRL sería un listado tasado y cerrado de competencias propias que tienen los municipios.

20 Velasco Caballero (2014a: 104-105) considera constitucional esta eliminación (que en todo caso no es sino una nueva muestra del escaso contenido materialmente efectivo de la garantía institucional de la autonomía local) aunque también entiende válidas las cláusulas equivalentes que tienen establecidas algunas Comunidades Autónomas.

21 Véase sobre los controles establecidos en el precepto para permitir su ejercicio, caso de que no se estén prestando por otra administración y que exista disponibilidad presupuestaria, Velasco Caballero (2014a: 88-91). Interesa señalar que estas competencias, según el propio contenido literal de la reforma, requerirán de estos procedimientos de control sólo caso de que sean nuevas: “A estos efectos, serán necesarios y vinculantes los informes previos de la Administración competente por razón de materia, en el que se señale la inexistencia de duplicidades, y de la Administración que tenga atribuida la tutela financiera sobre la sostenibilidad financiera de las nuevas competencias" (art. 7.4 in fine, el énfasis es nuestro). De modo que es perfectamente posible interpretar que todas las "competencias impropias" hasta la fecha ejercidas pueden seguir prestándose sin los informes en cuestión. Respecto de las competencias a la hora de emitir los informes, véase en 
la gestión autónoma (el nuevo art. 27 LRBRL detalla los procedimientos y controles para el ejercicio de competencias que puedan delegar las Comunidades Autómomas o el Estado ${ }^{22}$ );

- todo ello establece un marco global que aspira a limitar las competencias que ejercen los entes locales (aunque finalmente el esquema legal de la reforma aprobada considere como posibles, con matices, ampliaciones, pues las CC.AA. pueden delegar libremente empleando los mecanismos del art. 27 cualquier competencia y, como hemos señalado, no se entiende por qué no podrían, si quisieran, atribuirlas directamente como propias en las esferas de su competencia), lo que tiene la paradoja de que los entes locales municipales, al menos en el diseño estatal, quedan más limitados que las provincias para asumir competencias (al menos, tal y como parece que queda la regulación de éstas en la norma, Jiménez Asensio, 2013);

- mecanismos de delegación que degradan la autonomía local, tanto desde una perspectiva material (muchas competencias que aparecen como delegables podrían ser, y de hecho algunas eran hasta ahora, competencias propias de los municipios) como formal, en la medida en que establece tutelas para su ejercicio funcional (véase, de nuevo, la prolija regulación del art. 27 LRBRL en la redacción dada por la LRSAL y se comprenderá inmediatamente la profundidad del cambio, con la aparición, además, de tutelas adicionales en las DA $15^{\mathrm{a}}$, DT $1^{\mathrm{a}}$ y DT $2^{\mathrm{a}}$ respecto de cómo se realiza la “devolución" de competencias educativas, sanitarias y de servicios sociales ${ }^{23}$ ).

Lo sorprendente es, en todo caso, y como ya se ha dicho, la enorme amplitud con la que el gobierno parece concebir que puede operar el legislador en este campo y el hecho de que, quizás, no le falte (constitucionalmente, el menos en el diseño global, más allá de posibles excesos concretos) razón. Al margen de lo cual, por último, hay que mencionar que la ley, en la línea de lo que ya hizo en su día la LRBRL, pero de modo mucho más intenso, va mucho más allá de lo que parece razonable al establecer normas de organización interna (normas introducidas por la LRSAL en forma de nuevos artículos 75 bis, 75 ter 0104 bis, que establecen el nivel retributivo de los cargos locales o cuántos pueden ser los liberados, así como el número máximo de personal eventual que se autoriza a cada municipio a partir de su población). Y si bien el TC siempre ha establecido que la autonomía local lo es a un nivel diferente a la municipal, no puede perderse de vista que, en este punto, al menos, la jurisprudencia del Tribunal Constitucional español sí es bastante consistente a la hora de defender la estricta capacidad de autoorganización de las Comunidades Autónomas. De manera que, por ejemplo, nadie podría considerar constitucional una limitación de cargos públicos o retribuciones heteroimpuesta por una norma estatal a las Comunidades Autónomas. Sin embargo, parece evidente que una ya consolidada tradición de ordenación interna a cargo del legislador estatal hasta la fecha no objetada sí permitiría esta injerencia en el ámbito de autoorganización local. De hecho, nadie ha señalado que existan serios reparos constitucionales mayores a que así se haga, con el nivel de detalle e intromisión que propone la reforma, que es ciertamente notable ${ }^{24}$. Por mucho que las exigencias derivadas de la sostenibilidad económica, ya sea con el nuevo enunciado del art. 135 CE y ley de estabilidad mediante o incluso sin estos instrumentos normativos, aconsejen medidas de ahorro de esta índole y que siempre y en todo caso un desproporcionado crecimiento de este tipo de gastos sea criticable, la cuestión es hasta qué punto hay que entender que el control sobre esta cuestión corresponde, también, al legislador estatal o si, por el contrario, debería ser un asunto resuelto en el seno de la institución y a partir de los mecanismos de control democrático al uso. Más allá de cuál nos parezca que deba ser el punto óptimo de equilibrio respecto de esta cuestión a cada uno de nosotros, lo que sí parece evidente, en todo caso, es que la respuesta que da nuestro ordenamiento jurídico a este interrogante nos sitúa en un plano muy particular, donde el entendimiento y dimensión de la autonomía local no son excesivamente acusados ${ }^{25}$. En general, la idea de que ante las necesidades de ahorro autoimpuestas

Cebrián Abellán (2014: 109), la atribución dependiendo de si las Comunidades Autónomas han asumido o no ciertas competencias de tutela financiera de los entes locales.

22 Velasco Caballero (2014a: 105).

23 Estas normas son de muy dudosa constitucionalidad, tanto por imponer estas devoluciones (lo que es una llamativa intromisión en competencias autonómicas) como por el establecimiento de todas esas cautelas. Muy crítico con estos "traslados directos de competencias municipales" se ha mostrado Velasco Caballero, 2014a: 96-103.

24 Delgado Piqueras (2014: 336-342) sí señala algunas de las carencias legales en las que se enmarca el debate, pero tampoco en este caso parece que le plantee esta regulación dudas del tipo de las aquí expuestas.

25 Se da la paradoja de que, en el fondo, una intervención de esta índole, tan evidentemente reductora de la autonomía local, por mucho que establezca supuesta y formalmente unos máximos, uns techos que no pueden superarse, al eliminar los controles autónomos y heteroimponer reglas está, de alguna manera, "marcando" niveles que, sin duda, harán que los muchos ayuntamientos que a día de hoy están por debajo de esos límites (tanto en sueldos, como en número de liberados y asesores) sientan que, de alguna manera, el legislador estatal les está indicando que deben incrementar ese tipo de gastos. Puede darse la paradoja de que, al final de la historia, los ahorros en esta parcela tras la entrada en vigor de la norma sean más bien pequeños... cuando no inexistentes. 
o heteroordenadas deba ceder la autonomía local parece haber calado sin problemas. Hasta el punto de que no sólo la autonomía local sino las bases mismas de sus procedimientos de decisión democrática pueden ser puestos en cuestión si la situación (económica) lo requiere ${ }^{26}$.

En todo caso, y como es evidente, parece, además, y así lo justifica la propia norma en su Exposición de Motivos, que la idea de autonomía local queda restringida a partir de las nuevas atribuciones y competencias constitucionales que como consecuencia del Derecho europeo en la materia, de la reforma constitucional del artículo 135 CE y de su vinculación con el art. 149.1.14 a , han expandido enormemente el ámbito de acción estatal y sus posibilidades a partir de su novedoso entendimiento como omnipotente cláusula competencial horizontal, reduciendo enormemente, en proporción, otros. Es un cambio estructural y de una gran importancia en nuestro Derecho. Y no afecta sólo a la autonomía local, también lo hace al reparto competencial entre el Estado y las Comunidades Autónomas, como la reforma muestra también con claridad. Porque, en efecto, no se trata sólo de que hayamos transformado el modelo de régimen local de 1985 para restringir (al menos en línea tendencial y de principio) tanto la autonomía local como los ámbitos en que ésta se ejerce. Es que, además, se ha desplazado de la definición de estas cuestiones a las Comunidades Autónomas, asumiendo el Estado casi todo el espacio regulador.

\section{LA REFORMA COMO MECANISMO DE REDEFINICIÓN EN CLAVE CENTRALIZADORA DE LAS COMPETENCIAS SOBRE RÉGIMEN LOCAL}

La tramitación de la ley y en general todo el proceso previo de elaboración de la misma han puesto de manifiesto una evolución clara en la manera en que se entiende el reparto de competencias entre el Estado y las Comunidades Autónomas que, en este caso, no afecta sólo al gobierno y al legislador sino también al Tribunal Constitucional, que ya ha tenido ocasión de pronunciarse (STC 233/99, citada por la Exposición de Motivos de la ley) y que, aunque no ha planteado mayores objeciones a desarrollos competenciales generosos realizados por Comunidades Autónomas en sus Estatutos de Autonomía, con casos como el catalán o el andaluz con una regulación de sus regímenes locales internos muy extensa, tampoco ha puesto reparos a las manifestaciones de recentralización llevadas a cabo por el Gobierno sino todo lo contrario, entendiendo además siempre, en su jurisprudencia, que no hay que considerar que quepa una regla o principio general de “interiorización” del régimen local por parte de las Comunidades Autónomas o sus Estatutos (Sánchez Morón: 2011, 352-358). Tesis latente del Tribunal Constitucional que, además, no ha hecho sino reforzarse recientemente ${ }^{27}$.

Es cierto que la STC 31/2010, que es la más relevante respecto de esta cuestión de entre las más recientes que ha dictado nuestro Tribunal Constitucional, al analizar las pretensiones estatutarias referidas al caso catalán, no planteó objeciones mayores a una regulación extensa siempre y cuando fuera más o menos acomodable a la manera de entender el régimen local contenida en la norma básica estatal, sobre todo si hacemos una lectura con criterios interpretativos generosos a partir de su fallo e intentando generalizar algunas de sus soluciones (Velasco Caballero, 2011: 87-90). Con todo, la sentencia no se priva de señalar, eliminando mucha de la efectividad que podría tener este despliegue como norma capaz de crear dinámicas verdaderamente propias, que esta regulación es válida en tanto que acomodable a la del Estado, lo que abre la puerta a que cualquier cambio posterior de la misma, según el entendimiento que parece claro que está avanzando el Tribunal, pueda obligar a cambios por deseo del legislador estatal que, al parecer, sería en todo caso legislador básico y con unas restricciones atendiendo a este factor que son cada vez menores. Así, por ejemplo, la muy reciente Sentencia 104/2013, en respuesta a un recurso de inconstitucionalidad interpuesto por el parlament de Catalunya contra la ley 57/2003 de reforma del régimen local, ha confirmado punto por punto esta intuición, recordando que incluso allí donde pueda pretenderse que hay una interposición de un Estatuto de Autonomía, como es el caso catalán (la STC 104/2013, aunque resuelve un supuesto que tiene su origen antes de la aprobación del Estatuto catalán de 2006, es posterior a la ya mencionada STC 31/2010, que no se priva de mencionar), ésta no es tal y que el Estado, siempre y cuando actúe dentro de sus competencias, puede llevar la norma básica allí donde considere, por lo que las normas autonómicas, incluyendo

26 Es en este sentido particularmente insólita la DA $16^{\mathrm{a}}$ introducida por la reforma, que exceptúa la regla habitual (aprobación por el pleno) del presupuesto y otras medidas de gran importancia de tipo financiero en determinados supuestos: "Disposición adicional decimosexta. Mayoría requerida para la adopción de acuerdos en las Corporaciones Locales. 1. Excepcionalmente, cuando el Pleno de la Corporación Local no alcanzara, en una primera votación, la mayoría necesaria para la adopción de acuerdos prevista en esta Ley, la Junta de Gobierno Local tendrá competencia para aprobar: a) El presupuesto del ejercicio inmediato siguiente, siempre que previamente exista un presupuesto prorrogado. b) Los planes económico-financieros, los planes de reequilibrio y los planes de ajuste a los que se refiere la Ley Orgánica 2/2012, de 27 de abril. c) Los planes de saneamiento de la Corporación Local o los planes de reducción de deudas. d) La entrada de la Corporación Local en los mecanismos extraordinarios de financiación vigentes a los que se refiere la Ley Orgánica 2/2012, de 27 de abril, y, en particular, el acceso a las medidas extraordinarias de apoyo a la liquidez previstas en el Real Decreto-ley 8/2013, de 28 de junio, de medidas urgentes contra la morosidad de las administraciones públicas y de apoyo a Entidades Locales con problemas financieros. 2. La Junta de Gobierno Local dará cuenta al Pleno en la primera sesión que se celebre con posterioridad a la adopción de los acuerdos mencionados en el apartado anterior, los cuales serán objeto de publicación de conformidad con las normas generales que les resulten de aplicación".

27 Sobre la evolución de esta jurisprudencia, véase el detallado repaso que hace Alonso Mas (2014a: 88-109). 
el Estatuto de autonomía en su caso, deberán adaptarse, incluso aunque sea a posteriori, a esta realidad ${ }^{28}$. Cabe plantear adicionalmente, como es obvio, que siempre cabe hacer una "interpretación conforme al Estatuto" de la norma local básica (y es, por ejemplo, lo que propone Velasco Caballero, 2014b, dado que es conocido que el Tribunal Constitucional sí admite la función interpretativa del Estatuto respecto de las competencias estatales como recuerda Torres Muro -en Cosculluela Montaner y Carbonell Porras, 2011:63-), aunque la solución no es del todo satisfactoria porque ni es sencilla (porque no es fácil que sea pacífico cuál haya de ser esa interpretación), ni, sobre todo, funcionará razonablemente bien en un contexto donde los Estatutos de Autonomía de cada Comunidad Autónoma contuvieran una efectiva integración del régimen local y establecieran normas no necesariamente homologables por desarrollar modelos diferentes para sus regímenes locales propios. Como es evidente, la mejor y más fácil solución es la contención del legislador estatal. Es cierto, sin embargo, que en ausencia de ella sólo queda aspirar a esta interpretación "conforme a los Estatutos".

En este punto no deja de ser interesante comprobar hasta qué punto ha cambiado el entendimiento, probablemente el general de la comunidad jurídica, pero en todo caso el del Tribunal Constitucional, respecto a las posibilidades de delimitación competencial que se reconocen de facto al Estado a partir de títulos competenciales generales y a partir de sus facultades para establecer normas básicas. Respecto de la primera cuestión es patente la creciente ampliación de lo que el Tribunal Constitucional entiende que el Estado puede hacer con amparo en títulos como el artículo 149.1.1 ${ }^{\mathrm{a}}$ o, respecto del tema que nos ocupa, con una invocación tan genérica como la del 149.1.14a , explícitamente mencionada por la norma y que aparentemente puede acabar convirtiéndose, en conexión con el art. 135 CE en su nueva redacción, en un título competencial de enorme importancia que prácticamente habilitaría al Estado para realizar cualquier regulación sobre materias directa o indirectamente relacionadas con cuestiones de tipo económico, financiero o presupuestario. Por otra parte, como es patente, el otro título competencial invocado por la LRSAL, el 149.1.18a que permite al Estado desarrollar normativa básica en materia de régimen jurídico de las administraciones públicas, es patente que se interpreta en la actualidad con mucha mayor generosidad de la que, por ejemplo, era habitual cuando se enjuició la constitucionalidad de la ley 30/1992, donde toda una serie de preceptos fueron analizados con sumo cuidado por las SSTC 76/1996 y 89/1996 para sopesar hasta qué punto los preceptos eran o no efectivamente básicos. Entre que el Tribunal Constitucional en general ha acabado por conceder al legislador estatal carta blanca a estos efectos, con pocas excepciones como afecciones muy directas a la propia autoorganización de las Comunidades Autónomas, permitiendo incluso que normas reglamentarias o actos administrativos pasen en ocasiones por básicos y que concurren en este supuesto los anteriores títulos competenciales horizontales comentados (no así el art. 149.1.13 ${ }^{\mathrm{a}}$, que el legislador estatal finalmente ha dejado de invocar tras las críticas del Consejo de Estado al respecto), estamos asistiendo, en general, a una ampliación de la capacidad estatal para establecer normas básicas ciertamente notable (Bernadí Gil, 2010). Ampliación que conviene no perder de vista en la medida en que supone cambios estructurales de primer orden respecto del propio diseño estructural del Estado y sus equilibrios en el reparto territorial del poder.

Sin embargo, quizás en este caso podamos asistir a una situación que pueda acabar generando cierto freno a esta dinámica. No se puede perder de vista que, incluso si comparamos la situación actual con los recursos de que fue objeto la LRBRL, hay varios elementos que han cambiado y que han contribuido a dotar de estabilidad al sistema de régimen local español y, con él, al concreto reparto competencial que recoge. No sólo es que la LRBRL no haya sido sustancialmente modificada en este punto en casi tres décadas; es que, además, durante ese tiempo los Estatutos de Autonomía han ido desplegando efectos, las Comunidades Autónomas han ido consolidando su poder institucional y poniendo en marcha sus aparatos burocráticos, así como dictando normas propias en materia de régimen local, en algunos casos con mucho recorrido, por lo que a estas alturas es difícil, siquiera sea fácticamente, que el legislador estatal actúe como si desconociera toda esta realidad. Parte de este

28 En este ámbito, como resulta obvio, el legislador cuenta con cierto margen y puede optar, dentro de lo que es la referida doctrina del Tribunal Constitucional, por ser más generoso o menos con los desarrollos autonómicos previos y tratar de ser, en su caso, cuidadoso. La LRSAL establece, en este sentido, ciertas cautelas que, sin embargo, sorprendentemente, no tienen en cuenta a los territorios con regímenes locales autonómicos más ambiciosos ya incluidos en sus respectivos Estatutos de Autonomía (Cataluña y Andalucía). Además de las típicamente relacionadas con territorios forales (para una explicación de cómo afecta la reforma local a los llamados derechos históricos de Navarra y País Vasco en la materia, Razquin Lizarraga, 2014), los insulares, las CC.AA. uniprovinciales o Ceuta y Melilla sorprende la especial mención que se

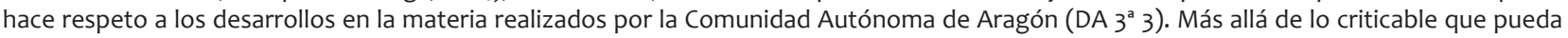
ser políticamente que se establezcan estas asimetrías de modo explícito en la norma, consecuencia de pactos de gobierno entre partidos nacionales y minorías nacionalistas y regionalistas, podría llegar incluso a plantearse si esta mención contiene algún elemento de arbitrariedad, que como es sabido está proscrita también al legislador según el art 9.3 CE y que, por mucho que no haya sido sólito entender que ha de ser un tamiz constitucional aplicable al legislador, en este caso no es descabellado, como mínimo, considerarlo. Cabe mencionar, por último, la posibilidad de que se puedan emitir objeciones al efectivo carácter de "básico" de una ley que introduce excepciones y diferenciaciones sin cuento que van más allá, incluso, de la existencia de diferencias efectivas, como es el caso de la previsión para Aragón. Probablemente, por mucho que el Tribunal Constitucional no haya indagado en exceso adentrándose en argumentos de este estilo hasta la fecha, un control de constitucionalidad estricto a partir de la idea de no arbitrariedad de los poderes públicos (art. 9.3 CE) y de la propia concepción de lo que deba ser una ley básica podría tener algo que decir al respecto. 
problema, en su vertiente política que no jurídica, ya hemos visto que efectivamente puede aparecer y limitar la voluntad estatal, como así ha sido forzando ciertos cambios durante la tramitación parlamentaria. Así, frente a leyes de régimen local como la aragonesa, la valenciana, la andaluza o la catalana que regulan de manera amplia y claramente incentivadora la gestión de servicios a partir de mecanismos de voluntariedad por parte de los municipios de tipo asociativo (mancomunidades, consorcios, etc.) la norma estatal, en el ALRSAL, optaba por una vía radicalmente contraria, poniéndoles trabas y extremando exigencias para tratar de llevarlos a su extinción. En gran parte, la rectificación que el PLRSAL introdujo y que explica la redacción final (no completa, como siempre, pero sí apreciable) de la norma de reforma finalmente aprobada en esta materia ${ }^{29}$ se explica por las dificultades evidentes de enfrentarse a estas prácticas consolidadas y a los problemas políticos que supone pretender liquidar instituciones y dinámicas consolidadas y en funcionamiento, haciendo un mero borrón y cuenta nueva, en un sistema donde el reparto territorial del poder no sólo existe desde hace décadas sino que está plenamente normalizado e interiorizado. Pero no sólo es un problema político. Jurídicamente no es excesivamente aventurado señalar que años de práctica y de funcionamiento han permitido ir decantando cuál sea el concreto contenido de lo básico, más o menos fijado a partir de una experiencia, enmarcada en la LRBRL, que permite señalar lo que efectivamente lo ha sido y lo que no (véanse, en este sentido, por ejemplo, las reflexiones de Velasco Caballero, 2007). Pretender uniformizaciones más allá de esta realidad es jurídicamente osado cuando están en manifiesta contradicción con las prácticas consolidadas. Al menos, si se considera que la garantía institucional que tantas veces hemos mencionado a lo largo de este trabajo tiene una mínima entidad jurídica y constitucional, por pequeña que sea. Y, en todo caso, al existir ahora diferentes Comunidades Autónomas con capacidad de respuesta jurídica y los medios y la experiencia para desarrollarla de manera técnicamente muy competente, la aprobación de esta ley permite augurar un enfrentamiento que tendrá que dilucidar el Tribunal Constitucional y que perfectamente podría empezar a suponer un reencuadramiento de lo básico en nuestro orden constitucional so pena de inclinarlo definitivamente hacia un neocentralismo con desconcentración en la gestión que se alejaría mucho del modelo pretendido por el constituyente (o, cuanto menos, del entendimiento general en décadas pasadas de lo que era el Estado de las Autonomías) ${ }^{30}$.

La ley de reforma del régimen local español finalmente aprobada contiene elementos adicionales, más allá del tema competencial en sentido estricto en que se apoya, que van en la línea de reducir la tradicional participación de las Comunidades Autónomas en el modelo de régimen local español que siempre había sido calificado, casi de forma tópica, como "bifronte". Así, como ya se ha dicho, recibió críticas generalizadas el mecanismo inicial del anteproyecto, que no sólo aspiraba a limitar las competencias locales a un listado fijado estatalmente sino a que éste no pudiera ser incrementado ni siquiera por las Comunidades Autónomas en materia de su exclusiva competencia. La pretensión era ciertamente llamativa, por cuanto, si las Comunidades Autónomas son competentes para el desarrollo legislativo de una materia, ¿qué razones pueden aducirse para no aceptar que puedan establecer competencias en esa materia a favor de los entes locales? ${ }^{31}$ Finalmente, tras las manifestaciones de generalizada

29 DT 11 ${ }^{a}$. LRASL: “Mancomunidades de municipios. En el plazo de seis meses desde la entrada en vigor de esta Ley, las mancomunidades de municipios deberán de adaptar sus estatutos a lo previsto en el artículo 44 de la Ley 7/1985, de 2 de abril, reguladora de las Bases de Régimen Local, para no incurrir en causa de disolución.

Las competencias de las mancomunidades de municipios estarán orientadas exclusivamente a la realización de obras y la prestación de los servicios públicos que sean necesarios para que los municipios puedan ejercer las competencias o prestar los servicios enumerados en los artículos 25 y 26 de la Ley 7/1985, de 2 de abril, reguladora de las Bases de Régimen Local.

El expediente para la disolución será iniciado y resuelto por el Órgano de Gobierno de la Comunidad Autónoma, y en todo caso conllevará:

a) Que el personal que estuviera al servicio de la mancomunidad disuelta quedará incorporado en las Entidades Locales que formaran parte de ella de acuerdo con lo previsto en sus estatutos.

b) Las Entidades Locales que formaran parte de la mancomunidad disuelta quedan subrogadas en todos sus derechos y obligaciones".

30 Véanse en este sentido manifestaciones muy significativas ya desarrolladas al margen de la evolución de posibles impugnaciones ante el Tribunal Constitucional de la norma estatal y su efectivo recorrido, que tienen como espacio de juego la confrontación de las voluntades legislativas de las Comunidades Autónomas con la del legislador estatal. Es el caso del ya referido Decreto-ley autonómico de Castilla y León 1/2014, de 27 de marzo, de medidas urgentes para la garantía y continuidad de los servicios públicos en Castilla y León, derivado de la entrada en vigor de la Ley 27/2013, de 27 de diciembre, de racionalización y sostenibilidad de la Administración Local o de su equivalente andaluz Decretoley $7 / 2014$, de 20 de mayo, por el que se establecen medidas urgentes para la aplicación de la ley 27/2013, de 27 de diciembre, de racionalización y sostenibilidad de la Administración local, de la ley gallega en tramitación parlamentaria con contenidos equivalentes y, sin duda, de otras actuaciones en esa misma dirección que están llamadas a aparecer y generalizarse.

31 Como es sabido, ha sido habitual entender que la ordenación de las normas reguladoras del régimen local y en concreto la interacción de la regulación que sobre el mismo comparten Estado y Comunidades autónomas, fruto del mencionado carácter bifronte, convertía las atribuciones competenciales contenidas en la ley básica estatal en una serie de competencias mínimas (por todos, Baño León, 2011: 646-649) que de esta forma conformarían una suerte de garantía que el Estado, por medio de su legislación básica, otorga a los entes locales, y sobre todo a su autonomía, frente a una posible inmisión de las Comunidades autónomas. Es manifiesto que la lógica de la nueva ley estatal se aleja de estos planteamientos, a pesar de estar consolidados en el entendimiento derivado de la práctica y de la jurisprudencia constitucional. Es ésta una cuestión que Zafra Víctor (2014: 65-70) critica severamente al Consejo de Estado, por cuanto en su Dictamen no ve cuestionable el 
perplejidad de la doctrina y las críticas del Consejo de Estado, el proyecto remitido a las Cortes pareció asumir la situación y abrió la mano, pero la norma ha acabado estableciendo toda una serie de cautelas respecto de cómo se habrán de realizar estas atribuciones competenciales que no dejan de resultar llamativas en la medida en que parecen apostar por la delegación (art. 27 LRBRL según la versión del texto de la LRSAL) como la única vía posible para la ampliación competencial, algo que ya hemos señalado como erróneo, muy cuestionado y que la práctica de las Comunidades Autónomas está poniendo directamente en tela de juicio por medio de su legislación sectorial (tanto la vigente como la nueva) y de las normas de adaptación a la nueva ley básica estatal32.

Con todo, las pretensiones de predeterminación del ejercicio de competencias de las Comunidades Autónomas no quedan reducidas al establecimiento de estas peculiares normas respecto de cómo atribuir competencias aun en supuestos en los que el Estado, constitucionalmente, no debería tener nada que decir. También, vía diferentes Disposiciones adicionales o transitorias al proyecto de ley, aparecen indicaciones respecto de cómo han de actuar Comunidades Autónomas y entes locales a la hora de repartirse funciones en materia de servicios sociales, educación o sanidad (las ya referidas DA $15^{\mathrm{a}}$, DT $1^{\mathrm{a}}$ y DT $2^{\mathrm{a}}$ son ejemplos paradigmáticos). Las reglas son llamativas, por cuanto además de dejar claro, como hemos señalado ya con anterioridad, que la voluntad del Estado es efectivamente imponer una "devolución de competencias"de los municipios a las Comunidades Autónomas, no sólo hacen eso sino que además introducen elementos, incluso evaluación del coste de las transferencias que a partir de las atribuciones estatales en materia de Haciendas Locales y estabilidad presupuestaria acaban por permitir ciertos controles a cargo del gobierno central que, desde un punto de vista competencial, son extraordinariamente extraños por no decir directamente extravagantes.

De nuevo, en este caso, aparece el art. 135 CE como perfecta excusa para una interferencia referida al ejercicio de competencias autonómicas en relación con los entes locales. Pero es que las consideraciones de eficiencia económica, a partir de cómo es ésta entendida por el Estado, parece que se convierten por el proyecto en un instrumento jurídicamente omnipotente que permiten al Estado entrar a regular cualquier aspecto de la organización administrativa sin importar a quién atribuya el reparto competencial constitucional la competencia en origen. Es lo que ocurre, también, con el nuevo modelo de gestión de los servicios públicos locales.

\section{EFICIENCIA Y GESTIÓN DE LOS SERVICIOS PÚBLICOS LOCALES: HACIA UN REDIMENSIONAMIENTO DE LOS MERCADOS DE SERVICIOS Y LA GESTIÓN PRIVADA DE LOS MISMOS}

La reforma, en su pretensión de lograr ese ahorro económico tan publicitado (los famosos y quiméricos 8.000 millones de euros señalados por la Unión Europea), persigue el objetivo de hacer más eficiente la Administración local española, como el propio nombre de la norma señala al hablar de "sostenibilidad y racionalización" de la Administración local. Ello se canaliza a partir de una serie de medidas que se pueden sintetizar en cuatro grandes ejes:

- Limitación de las competencias y gastos asociados a las mismas (como ya hemos visto, nuevos arts. 7, 25, 26, 27 LRBRL, supresión del art. 2833)

- Establecimiento de normas de funcionamiento exigentes y limitadoras, entre las que se encuentran las referidas a sueldos o número de asesores, pero también otras que refuerzan ciertas funciones de la intervención y los funcionarios con habilitación estatal (nuevos arts. 75 bis, 75 ter 0104 bis LRBRL, entre otros).

- Obsesión por el tamaño de los municipios españoles y su excesivo número (son realidades conectadas, pues reducir el número de municipios incrementaría el tamaño de los resultantes, nuevo art. 13 LRBRL)

- Apuesta por un nuevo modelo de organización de la prestación de los servicios públicos locales, a partir de la creación de mercados de mayor dimensión territorial, tendencialmente provinciales (nuevos arts. 26.2 y 36 LRBRL).

cambio de paradigma que supone pasar de entender la labor de las bases estatales como de determinación de esta garantía de mínimos a pretender aspirar a establecer, por el contrario, máximos.

32 En este sentido, también Alonso Mas (2014a: 111-113), sensatamente, señala que del mismo modo que las normas autonómicas, incluyendo las estatutarias, pueden tener como canon de constitucionalidad la normativa básica estatal ello es así si y sólo si la mencionada ley (como en este casos la LRSAL) respeta el reparto constitucional de competencias, algo que no parece que sea el caso si pretende intervenir en la ordenación de prestaciones sectoriales de competencia autonómica exclusiva o si se desvía de la mencionada práctica y entendimiento constitucional de la lista de competencias definidas en la norma básica estatal como un mecanismo por el que el Estado, en su ley básica, dotaría de garantía a los municipios respecto de unas competencias mínimas que las Comunidades Autónomas habrían de respetar pero no en el sentido de lista cerrada. Entiende por ello que, en su caso, lo que habría que reputar inconstitucional sería, por ello, la ley estatal de reforma local en estos puntos, por lo que la actuación autonómica seguiría siendo posible.

33 Velasco Caballero (2014b: 69-71). 
Las cuestiones referidas a los dos primeros puntos han sido ya mencionadas al analizar las consecuencias de la norma respecto de la autonomía local y del reparto competencial entre Estado y Comunidades Autónomas. En cuanto al tamaño de los municipios, más allá de señalar que, de nuevo, el Estado incide al regular las fusiones en cuestiones que desde el despliegue autonómico venían reguladas por consolidadas normas autonómicas, de modo que se reproducen aquí algunos de los problemas ya expuestos, tiene sentido explicitar que la apuesta por municipios más o menos grandes, en tanto que elección política, va más allá de lo que el Derecho pueda decir al respecto en sí misma considerada. No es, sin embargo, neutro quién tome estas decisiones, por la cuestión competencial referida. Como tampoco lo es cuál sea el procedimiento establecido para la fusión o absorción de municipios.

En los términos del ALRSAL, y más allá de que pueda cuestionarse que algunos de los casos que permitían la fusión forzosa pudieran ser respetuosos con la autonomía local, discusión bizantina que parece hace tiempo resuelta entendiendo que los municipios pueden fusionarse o agruparse sin necesidad de contar con su acuerdo a partir del cumplimiento de unos mínimos procedimentales y participativos, la cuestión más interesante que suscitaba la norma en su redacción inicial era de oportunidad. Existían dudas respecto de si un modelo como el que se plasmaba en la norma respeta el principio de subsidiariedad y que, por ello, fuera en verdad eficiente. Al menos por la evidente contradicción entre la obsesión por incrementar el tamaño de los municipios y, a la vez, eliminarles competencias, lo que parece un contrasentido y además invalida el ejemplo comparado que solía aducirse a favor de la medida por cuanto los países de nuestro entorno que han procedido a incrementar el tamaño de los municipios no les han retirado competencias sino que, antes al contrario, suelen ser aquellos que no tienen entes intermedios entre el Estado y los municipios, razón por la cual ejercen no pocas competencias que en España, habitualmente, están en manos de las Comunidades Autónomas (véanse en este sentido las experiencias comparadas de dimensión y reforma recogidas en Moreno Molina, 2012). En todo caso, con las modificaciones introducidas finalmente, al volver a tratarse este tema desde un prisma de voluntariedad, aunque sea con incentivos económicos (medida, por lo demás, inteligente y muy apropiada en contextos de reparto del poder entre diversos niveles territoriales para tratar de orientar políticas públicas ${ }^{34}$ ), las reticencias jurídicas que pudieran albergarse decaen en su mayoría. A este respecto, pueden subsistir únicamente dudas respecto de si en un sistema constitucional como el nuestro la aplicación del principio de no discriminación puede entenderse que padece por este tipo de medidas incentivadoras, pero es un debate complejo que se aleja de las reflexiones que ahora nos ocupan (en este sentido, es interesante, pero parcial y dándole más sentido legitimador del que realmente tiene, la cita de la STC 103/2013 que hace la Exposición de Motivos de la norma: se trata, en todo caso, de un debate que en España acabaremos teniendo, como en otros Estados con el poder territorialmente compartido, si avanzamos en un entendimiento más federal e incentivador de ciertas acciones estatales sobre cuestiones donde intervienen varios niveles de gobierno).

Por último, es extraordinariamente importante señalar, como ha recordado Tejedor Bielsa (2013) que en el fondo una de las grandes claves de esta reforma local es la modificación, por un mecanismo indirecto, de la manera en que se prestan los servicios públicos locales ${ }^{35}$. Por mucho que hayan desaparecido gran parte de los mecanismos que establecían sistemas que coactivamente residenciaban, gustara o no a los municipios afectados, la prestación de sus servicios públicos (o al menos de algunos de ellos) en las Diputaciones provinciales (y que

34 No obstante, si analizamos con atención la batería de medidas de fomento del artículo 13.4 LBRL tal y como queda redactado tras la LRSAL, los incentivos no parecen tantos ni tan generosos: un o'10 de coeficiente de ponderación en los ingresos previstos por la LRHL, una garantía de que el esfuerzo inversor que recibirá el municipio resultante de la fusión será al menos equivalente al que ya se tenía y de que la financiación mínima será la suma de las de ambos municipios por separado sin que pueda descender, garantías de que no habrá pérdidas en otros impuestos, cinco años (ampliables) de preferencia en planes de cooperación o equivalentes y la dispensa de prestar los nuevos servicios obligatorios que pudieran corresponderle por el aumento poblacional. No parecen medidas de incentivo que puedan reputarse excesivas sino, más bien, ciertamente rácanas. En el fondo parecen más bien medidas orientadas a tratar de evitar posibles problemas futuros de tipo económico derivado de la fusión, esto es, garantizar que no se derivarán de la misma perjuicios que provocarían que no sólo no suponga ventajas sino que, directamente, no salga a cuenta. Contrasta este modelo con las agregaciones voluntarias que los países federales (EE.UU.; Alemania...) incentivan de forma mucho más generosa o incluso con las agrupaciones funcionales metropolitanas que están imponiéndose en Francia, voluntariamente, a cambio de competencias y financiación, que están funcionando muy bien. Sobre la conveniencia de incentivar mecanismos colaborativos para un mejor ejercicio de competencias locales empleando estas vías, Boix Palop (2013a: 170-176).

35 El mecanismo es indirecto porque la reforma no modifica las formas jurídicas de prestación de los servicios públicos locales. El actual art. 85.2, tras la reforma, sigue permitiendo que los servicios públicos de competencia local se gestionen, eso sí, "de la forma más sostenible y eficiente", a partir de mecanismos de gestión directa como la gestión por la propia Entidad Local, por medio de un Organismo autónomo local, empleando una Entidad pública empresarial local , por último, por medio de una Sociedad mercantil local cuyo capital social sea de titularidad pública (la única novedad es que la ley trata de desincentivar estas dos últimas fórmulas, obligando a una memoria que justifique, caso de que se opte por ellas, su mayor conveniencia). Como alternativa a la gestión directa, siguen los mecanismos de gestión indirecta mediante las distintas formas previstas para el contrato de gestión de servicios públicos en el texto refundido de la Ley de Contratos del Sector Público, aprobado por Real Decreto Legislativo 3/2011, de 14 de noviembre. Sorprendentemente, para optar por la gestión indirecta, en cambio, no es preciso informe ni memoria técnica alguna que justifique o documente ahorros o una mayor eficiencia o calidad prestacional, en lo que no deja de ser una curiosa asimetría. 
dependían de una evaluación de costes y la supuesta superación de unos costes estándar que debían ser definidos reglamentariamente, mecanismo muy criticado incluso por el Consejo de Estado por su indeterminación), ello no quita para que la idea, ahora por vías indirectas (obligación de publicar costes efectivos de la prestación de los servicios en cada municipio y su control posterior por las diputaciones, así como su publicación ${ }^{36}$ ), siga siendo la misma: tratar de ir llevando poco a poco la prestación de los servicios públicos locales de los municipios de más de 20.000 habitantes a unas estructuras de prestación de base provincial lideradas por las Diputaciones provinciales.

Las consecuencias de estos cambios no son sólo de orden de magnitud. También hay elementos cualitativos en la transformación y desplazamiento operados. No es lo mismo que se centralice la contratación de ciertos servicios a que lo hagan los ayuntamientos individualmente. El tamaño y origen de las empresas que van a concursar no será el mismo en un caso y otro. Incluso, como es obvio, este mecanismo no es neutro a efectos del modelo de gestión que acabará implantándose (resulta evidente que es mucho más factible la prestación directa municipio a municipio que por medio de una diputación provincial que deba hacerse cargo, a la vez, de muchos servicios en muchos municipios a veces separados geográficamente y con características y necesidades dispares). La conclusión que parece esbozarse a partir de estas coordenadas es que la reforma local llevada a cabo por la LRSAL, por la vía de fomentar la prestación del servicio a cargo de las Diputaciones (e incluso forzarla, en algunos casos extremos), está en la práctica incentivando un sistema de prestación más indirecto, más privado, más externalizado y en manos de empresas más grandes ${ }^{37}$. Lo cual no tiene necesariamente siempre sentido. Hay quien ha señalado que dependiendo de unos servicios u otros, económicamente, tendrá más sentido un modelo u otro (Bel, 2013), pero sin que siempre la solución deba ser agregar territorialmente la prestación. Y, por último, es dudoso a partir de la evidencia empírica que la corrupción se reduzca sustancialmente por el simple motivo de elevar de nivel la gestión, como el ejemplo danés, por ejemplo, muestra (Cuñat, 2013).

Debe señalarse que esta conclusión contiene elementos paradójicos, alguno muy visible en preceptos como el nuevo art. 85.2 LRBRL, que, como se ha señalado, para optar por ciertas modalidades de prestación directa de los servicios públicos locales exige una detallada memoria económica justificativa de la conveniencia, en términos de eficacia y economía, de la modalidad elegida pero que, en cambio, exime de este requisito cuando la opción elegida es la gestión indirecta. Algo que no plantearía problemas si pudiéramos asumir que esta última va a ser siempre más eficiente y económica que la gestión directa, pero la evidencia empírica no es ésta sino, en muchos casos, la contraria (como por ejemplo el Tribunal de Cuentas ha demostrado en su reciente Informe de fiscalización de servicios públicos locales para el ejercicio 2011, donde se constata, antes al contrario, una generalizada situación de sobrecoste en los casos de servicios prestados por empresas privadas en comparación con los servicios homologables prestados por ayuntamientos equiparables de forma directa $\left.{ }^{38}\right)$. Queda pues claro, con ejemplos como éste, que la ley ha antepuesto en muchos casos una voluntad de reforma de los mercados que tiene como base otras razones antes que la pura eficiencia económica o el intento de eliminar incentivos para la corrupción. Máxime si tenemos en cuenta que el informe del Tribunal de Cuentas a que nos referimos analiza, precisamente, servicios como los que el art. 26 de la ley pretende encargar de forma muy general a las Diputaciones provinciales (y previsiblemente, por lo ya expuesto, por medio de la gestión indirecta) ${ }^{39}$.

36 La medida es importante para la prestación de los servicios que el art. 26.2 prevé que, en principio, la Diputación coordina para municipios menores de 20.000 habitantes (recogida y tratamiento de residuos, abastecimiento de agua potable a domicilio y evacuación y tratamiento de aguas residuales, limpieza viaria, acceso a los núcleos de población, pavimentación de vías urbanas y alumbrado público). En estos casos, recordemos, la Diputación propone, pero siempre con la conformidad de los municipios afectados, al Ministerio de Hacienda y Administraciones Públicas la forma de prestación, consistente en la prestación directa por la Diputación o la implantación de fórmulas de gestión compartida a través de consorcios, mancomunidades u otras fórmulas. Para todo este proceso se han de aportar los costes efectivos de los servicios prestados por los municipios, con la idea de generar mecanismos de incentivo para el ahorro y de justificar la coordinación o asunción de los mismos por las Diputaciones provinciales. El art. 36 de la ley local en el texto surgido de la reforma otorga a las Diputaciones provinciales competencias para controlar el coste efectivo de los servicios ofrecidos por los municipios de su provincia y la responsabilidad de elaborar anualmente un plan de prestación y coordinación de servicios donde ha de tener en cuenta objetivos y costes efectivos. Cuando la Diputación detecte que los costes efectivos de los servicios prestados por los municipios son superiores a los de los servicios coordinados o prestados por ella, incluirá en el plan provincial fórmulas de prestación unificada o supramunicipal para reducir sus costes efectivos. A efectos del cálculo de estos costes, el art. 116 ter obliga a todos los municipios a llevarlo a cabo anualmente, a su comunicación al Ministerio de Hacienda y Administraciones Públicas y a su posterior publicación por parte de éste. El procedimiento para determinar el cálculo de los mismos, como es obvio, es esencial para el buen funcionamiento de todo el sistema (y queda a expensas de su ordenación por orden ministerial). Sobre las diferencias entre esta fórmula y la inicialmente contenida en la ley, muy criticada por el Consejo de Estado en su dictamen, en torno a la definición de costes "estándar", véase Zafra Víctor (2014).

37 Redondo (2013) aporta datos sobre la estructura de costes de las Diputaciones provinciales en España que ponen de manifiesto su incapacidad estructural para, a día de hoy, prestar por sí mismas los servicios que de ella dependen. Motivo por el cual tienden a externalizar cada vez más sus acciones. Esta tendencia sólo puede ir a más si reciben más competencias y han de garantizar la prestación de más servicios.

38 Este estudio, presentado de forma coetánea a la aprobación de la ley, convirte en más incomprensible la asimetría a la que nos referíamos antes respecto de la no exigencia de justificación adicional cuando un municipio opta por la gestión indirecta, mientras que sí se requiere ese estudio si se opta por la gestión directa por medio de una sociedad pública (art. 85.2 LRBRL).

39 En efecto, en el citado informe (pp. 61-114) se estudian los resultados de la prestación de servicios como el de alumbrado, recogida 
La solución final de la reforma legal aprobada por medio de la LRSAL, salvo las excepciones reseñadas, va en la línea de no imponer sino fomentar o "forzar" por medio del soft-law (publicidad, comparación, promoción del Plan de coordinación de servicios provincial, medidas de fomento y atractivo de la gestión a cargo de la Diputación) el que cada vez más municipios pequeños opten por delegar en las Diputaciones provinciales más y más servicios. En principio, nada que objetar a que así se haga si efectivamente hay mejoras de eficiencia (y los mecanismos ahora dispuestos en los arts. 26.2 y 116 ter de la LRBRL para garantizar la publicidad y transparencia de los costes pueden ser útiles, en efecto, para detectar dónde puedan producirse). Únicamente es cuestionable si tienen sentido las transferencias coactivas justificadas en razones ajenas a la eficiencia (incumplimiento del municipio de sus obligaciones en materia de estabilidad financiera, que pueden no tener nada que ver, o no tener que ver directamente, con problemas de eficiencia en la prestación del servicio) y respecto de los costes efectivos si las dimensiones provinciales y, sobre todo, una estructura como las Diputaciones provinciales son las más adecuadas para llevar a cabo estas tareas. La literatura comparada (Lago Peñas y Martínez Vázquez, 2013), como es sabido, pone de manifiesto que las agregaciones en esta materia funcionan mucho mejor a partir de sistema de voluntariedad, pero quizás la voluntariedad debería también extenderse no sólo a querer entrar o no en el sistema sino a qué tipo de modelo de prestación y ámbito elegir. Por ejemplo, con una potenciación de mecanismos asociativos que, en cambio, la reforma sigue viendo como sospechosos y que cuentan no sólo con cierta tradición sino con el apoyo de las normas de régimen local autonómicas más modernas que, por lo general, han apostado decididamente por estas vías (Boix Palop, 2013a: 150-160; 170-176).

Por último, hay que señalar que quedan no pocos problemas prácticos por resolver respecto de la concreta articulación de los mecanismos de asunción por parte de las Diputaciones de este tipo de prestaciones, esencialmente a la hora de determinar cómo imputar deudas (pasadas o futuras) al reparto del esfuerzo económico tanto presente como por venir, por ejemplo.

\section{CRÍTICAS AL MODELO PLASMADO EN LA LEY DE REFORMA LOCAL Y A SUS INSUFICIENCIAS}

A partir de las consideraciones hasta aquí realizadas es fácil aventurar que la valoración global que merece la reforma de nuestro régimen local tan trabajosamente perfilada por el gobierno y finalmente aprobada parlamentariamente no es demasiado positiva. En primer lugar, porque el resultado denota una descorazonadora ausencia de modelo global que nada bueno puede traer, sino confusión, amén de exigir un enorme esfuerzo a intérpretes y entes locales para que sustancialmente, a la postre, las cosas sigan siendo más o menos como la razonable práctica seguida hasta ahora ha asentado. En segundo lugar, porque es francamente dudoso que vaya a producir excesivo ahorro económico (al menos, a igual prestación de servicios públicos, otra cosa es si la traslación de ciertas competencias a las Comunidades Autónomas hace que los servicios hasta ahora prestados por los ayuntamientos dejen de prestarse pero, al menos en teoría, se supone que no es ésa la idea) y manifiestamente imposible que se llegue a los famosos 8.000 millones de euros inicialmente planteados como objetivo de ahorro. Además, la norma plantea no pocas contradiciones internas de calado que convierten en sospechosas muchas de sus soluciones y permiten aventurar que pueden acabar por ser poco aplicadas y sencillamente puenteadas por la práctica local a partir del desarrollo, como ya se está produciendo, de las competencias de las Comunidades Autónomas. El ejemplo comparado en que dice inspirarse la norma, de hecho, no avala que la reducción del número de municipios y el incremento de su tamaño vayan de la mano de una drástica reducción de competencias. Tampoco parece que haya una elaboración realista de alternativas a la prestación de los numerosos servicios (por ejemplo, sociales, con la importancia que ello tiene para los ciudadanos) que están garantizando los ayuntamientos y que la norma pretende que dejen de ser de su incumbencia, lo que induce a pensar que las famosas "competencias impropias" van a seguir teniendo una larga vida, mal que le pese al gobierno, por pura necesidad... y porque hay no pocas vías de escape jurídicas para que esas necesidades, comprobadas y patentes, que por ello han generado unas dinámicas prestacionales de proximidad, puedan seguir cubriéndose (y porque, además, tanto Comunidades Autónomas como entes locales tienen claro que es mejor que así sea $\left.{ }^{40}\right)$.

de residuos, abastecimiento de agua potable o limpieza viaria para municipios de menos de 20.000 habitantes y los diversos costes según las cuentas rendidas. Llama la atención que el estudio, que por primera vez acomete estas comparaciones (claramente inspirado por el proceso de reforma local) no haya logrado a su vez orientar algunas de las medidas legalmente aprobadas, pues de haberlo tenido en cuenta no sólo se habría obligado a extremar las cautelas respecto de la gestión indirecta de estos servicios sino que, incluso, podría haber sido puesto en cuestión el ideario global y de fondo en este punto de la ley, dado que el informe del Tribunal de Cuentas, como mínimo, permite albergar dudas sobre la efectiva existencia de muchas de las publicitadas economías de escala con las que se ha justificado la reforma local.

40 Cuestión diferente son las consecuencias presupuestarias que pueden derivarse de que esta prestación sea considerada “competencia propia” por atribución autonómica o, por el contrario, competencia “impropia” del 7.4 LRBRL que se presta por, entre otras razones, tener disponibilidad presupuestaria. Cuestión ésta que ya está dando origen a no pocos posicionamientos estratégicos cuyo análisis, en todo caso, no nos compete aquí y que está dando lugar a una pelea entre municipios, comunidades autónomas, FEMP y el propio gobierno central que tiene poco que ver con la ortodoxia jurídica y mucho con planteamientos tacticistas basados en tratar de buscar una interpretación de cómo nuestro Derecho ordena el reparto comptencial que conlleve minimizar las obligaciones propias de financiación y las desplace a otras 
En todo caso, estamos ante un ejemplo claro de un programa de recentralización jurídica que demuestra la desconfianza del gobierno en la autonomía (en este caso, particularmente, en la autonomía local). Con independencia de la (legítima) opinión que pueda tenerse al respecto y de que muy posiblemente la poca densidad constitucional de la garantía institucional de la autonomía local permite, en efecto, al legislador adoptar este modelo, es necesario identificar la clara orientación de las medidas contenidas en la LRSAL y no parece descabellado apelar tanto al ejemplo comparado como a ciertos principios comunes del Derecho europeo que también pueden rastrearse en nuestra Constitución, aunque sea in fieri en algunos casos (subsidiariedad, eficiencia, principio democrático, participación y control ciudadanos...), para considerarlas francamente poco acertadas. Es muy probable que estemos ante una norma que demuestre en el futuro, con contadas excepciones (los mecanismos de incentivo, de soft-law, de publicidad y transparencia no son criticables, antes al contrario), poca capacidad de introducir mejoras efectivas en la gestión y vida diaria de nuestras Administraciones locales pero que, a cambio, pueda producir conflictos de importancia si se pretenden llevar rígidamente a la práctica sus previsiones en materia de repliegue competencial de los ayuntamientos en unos momentos de ajuste presupuestario que muy probablemente dificultarán que las Comunidades Autónomas los puedan prestar en condiciones, con la consiguiente merma de atención a los ciudadanos en general y a los vecinos más desfavorecidos en particular.

\section{BIBLIOGRAFÍA}

- Alesina, Alberto y Spolaore, Enrico (2003), The Size of Nations, MIT Press.

- Almeida Cerreda, Marcos (2013), "La reforma de la planta, organización, articulación y estructura competencial de la Administración local”, La reforma local, Publicaciones AEPDA, disponible ponencia en http://www.aepda.es/AEPDAAdjunto-463-Ponencia-Prof-Almeida-Cerreda.aspx (consulta 1 de mayo de 2014).

- Alonso Mas, María José (2014a), “Normas básicas sobre régimen local, estatutos de autonomía y normas autonómicas de desarrollo", en M. Domingo Zaballos (coord.), Reforma del régimen local. La ley de racionalización y sostenibilidad de la Administración local: veintitrés estudios, Thomson Reuters Aranzadi, 2014, pp. 85-117.

- Alonso Mas, María José (2014b), “El nuevo régimen de las competencias municipales", en M. Domingo Zaballos (coord.), Reforma del régimen local. La ley de racionalización y sostenibilidad de la Administración local: veintitrés estudios, Thomson Reuters Aranzadi, 2014, pp. 155-188.

- Arenilla Sáez, Manuel (2014), “El nuevo sistema de competencias locales”, en J.A. Santamaría Pastor (ed.) La reforma de 2013 del régimen local español, Fundación Democracia y Gobierno Local, pp. 15-55.

- Baño León, José María (1988), "La distinción entre derecho fundamental y garantía institucional en la Constitución española", Revista española de Derecho constitucional, n²4, pp. 155-179.

- Baño León, José María (2011), “La ordenación de las normas reguladoras del régimen local”, en S. Muñoz Machado (dir.), Tratado de Derecho Municipal, tercera edición, lustel, pp. 643-716.

- Bel, Germà (2013), "Local governement size and efficiency in capital-intensive services: what evidence is there of economies of scale, density and scope?, The Challenge of Local Government Size, Edward Elgar, 2013, pp. 148-170..

- Bernadí Gil, Xavier (2010), "La doctrina de la Sentencia 31/2010 sobre las competencias ejecutivas (sostenella e no enmendalla)", en Revista de Dret Públic, nº extra 1-2010, pp. 262-270

- Boix Palop, Andrés (2013a), Una nova planta per als valencians. Possibilitats i límits per a l'organització política i administrativa del País Valencià dins la Constitució de 1978, Fundació Nexe.

- Boix Palop, Andrés (2013b), “40.000 millones de euros y de unicornios reformando la Administración”, en el blog jurídico No se trata de hacer leer, disponible en http://www.lapaginadefinitiva.com/aboix/?p=861 (consulta 1 de mayo de 2014).

- Carbonell Porras, Eloísa (2013), "La planta del gobierno local”, La reforma local, Publicaciones AEPDA, disponible ponencia en http://www.google.es/url?sa=t\&rct=j\&q=\&esrc=s\&source=web\&cd=1\&ved=0 CDEQFjAA\&url=http\%3A\%2F\%2Fwww.aepda.es\%2FAEPDAAdjunto-456-Ponencia-Prof-Carbonell-Porras. aspx\&ei=BDxzU7WwE-qmoQX6JA\&usg=AFQjCNGo8pAirs19KwDdoEjpfQqTbrCt6Q\&sig2=8oDOCGelXtZ pfl7Cw1xKfg\&bvm=bv.66699033,d.d2k (consulta 1 de mayo de 2014).

Administraciones (lo que da lugar a interpretaciones peregrinas y muy incoherentes, como es natural). 
- Cea Alaya, Ángel (2014), "La contratación administrativa y la reforma de la Administración pública”, Contratación administrativa práctica, n 130, pp. 22-30.

- Cebrián Abellán, Manuel (2014), El régimen local tras la reforma de la ley de racionalización y sostenibilidad, Le Ley-El Consultor- Bosch.

- Comisión para la Reforma de las Administraciones públicas, Reforma de las Administraciones Públicas, disponible en la web de la comisión http://www.seap.minhap.gob.es/dms/es/areas/reforma_aapp/ INFORME-LIBRO/INFORME\%2OLIBRO.PDF (consulta 1 de mayo de 2014).

- Cosculluela Montaner, Luis y Carbonell Porras, Eloísa (dirs.) (2011), Reforma estatutaria y régimen local, Civitas-Thomson Reuters.

- Cuñat, Vicente (2013), “Corrupción municipal (¡en Dinamarca!)”, Nada es Gratis.

- Consejo de Estado (2013), "Dictamen sobre el Anteproyecto de Ley de Racionalización y Sostenibilidad de la Administración Local”, Boletín Oficial del Estado, Dictamen de 26 de junio de 2013.

- Delgado Piqueras, Francisco (2014), "El redimensionamiento de las retribuciones de los cargos públicos locales", en M. Domingo Zaballos (coord.), Reforma del régimen local. La ley de racionalización y sostenibilidad de la Administración local: veintitrés estudios, Thomson Reuters Aranzadi, 2014, pp. 333-371.

- Embid Irujo, Antonio (2012), La constitucionalización de la crisis económica, lustel.

- Embid Irujo, Antonio (2014), “Los efectos de la crisis económica sobre las instituciones públicas”, El Cronista del Estado Social y Democrático de Derecho, nº 43, pp. 64-72.

- Forcadell i Esteller, Xavier (2014), "Aproximación crítica a los principales cambios en la legislación de régimen local como consecuencia de la aprobación de la ley 27/2013, de 27 de diciembre, de racionalización y sostenibilidad de la Administración Local”, en J.A. Santamaría Pastor (ed.) La reforma de 2013 del régimen local español, Fundación Democracia y Gobierno Local, pp. 57-73.

- Jiménez Asensio, Rafael (2013), "El Proyecto de Ley de Racionalización y Sostenibilidad de la Administración Local: novedades más relevantes en relación con los borradores del LRSAL y principales enmiendas aprobadas en el Congreso de los Diputados", Diario del Derecho Municipal.

- Jordana de Pozas, Jesús (1956), "Las comisiones para la reforma administrativa”, Revista de Administración Pública, nº 21, pp. 215-224.

- Lago Peñas, Santiago y Martínez Vázquez, Jorge (ed.), The challenge of local government size, Edward Elgar.

- Medina Guerrero, Manuel (2014), La reforma del régimen local, Tirant lo Blanch.

- Menéndez, Agustín (2014), "Los efectos de la crisis económica sobre las instituciones públicas", El Cronista del Estado Social y Democrático de Derecho, nº 43, pp. 64-72.

- Moreno Molina, Ángel Manuel (ed.) (2012), Local government in the Member States of the European Union: a comparative legal perspective, INAP.

- Muñoz Machado, Santiago (2013), "Ocho mil millones de euros de ahorro: la compleja reforma de la Administración Local”, Posiciones Círculo Cívico de Opinión, 7 de mayo de 2013.

- Parejo Alfonso, Luciano (2011), "La autonomía local en la Constitución española”, en S. Muñoz Machado (dir.), Tratado de Derecho municipal, tercera edición, lustel, pp. 47-210.

- Razquin Lizarraga, Martín María (2014), "Reforma local y derechos históricos: Navarra y País Vasco", en M. Domingo Zaballos (coord.), Reforma del régimen local. La ley de racionalización y sostenibilidad de la Administración local: veintitrés estudios, Thomson Reuters Aranzadi, 2014, pp. 85-152.

- Redondo, Juan Luis (2013), "La Diputación provincial, esa gran desconocida... y algunos datos para empezar a conocerla", en el blog Hay Derecho, disponible http://hayderecho.com/2013/10/24/la-diputacionprovincial-esa-gran-desconocida-con-algunos-numeros-para-empezar-a-conocerla/ (consulta 1 de mayo de 2014).

- Santamaría Pastor, Juan Alfonso (2014), "El régimen de las competencias locales y el dilema de la esfinge", en J.A. Santamaría Pastor (ed.) La reforma de 2013 del régimen local español, Fundación Democracia y Gobierno Local, pp. 139-156. 
- Sánchez Morón, Miguel (2011), “La distribución de competencias entre el Estado y las Comunidades Autónomas”, en S. Muñoz Machado (dir.), Tratado de Derecho municipal, tercera edición, lustel, pp. 337389.

- Tejedor Bielsa, Julio (2013), “Autonomía, economía y reforma local”, Agenda Pública, 10 de octubre de 2013.

- Tribunal de Cuentas (2013), Informe n 1010, Fiscalización del Sector Público Local (Ejercicio 2011), disponible en http://hayderecho.com/2013/10/24/la-diputacion-provincial-esa-gran-desconocida-con-algunosnumeros-para-empezar-a-conocerla/ (consulta 1 de mayo de 2014).

- Velasco Caballero, Francisco (2007), “Autonomía local”, Actas II Congreso AEPDA.

- Velasco Caballero, Francisco (dir.) (2010), Gobiernos locales en Estados federales y descentralizados: Alemania, Italia y Reino Unido, Institut d'Estudis Autonòmics.

- Velasco Caballero, Francisco (2013), "Sobre el Dictamen del Consejo de Estado en relación con el Anteproyecto de Ley de Racionalización y Sostenibilidad de la Administración Local”, Instituto de Derecho Local - Universidad Autónoma de Madrid.

- Velasco Caballero, Francisco (2014a), "Títulos competenciales y garantía constitucional de la autonomía local en la Ley de Racionalización y Sostenibilidad de la Administración Local”, en J.A. Santamaría Pastor (ed.) La reforma de 2013 del régimen local español, Fundación Democracia y Gobierno Local, pp. 139-156.

- Velasco Caballero, Francisco (2014b), “La ley de racionalización y sostenibilidad de la Administración local en el sistema de Derecho local”, en M. Domingo Zaballos (coord.), Reforma del régimen local. La ley de racionalización y sostenibilidad de la Administración local: veintitrés estudios, Thomson Reuters Aranzadi, 2014, pp. 45-83.

- Vidal Monferrer, Rosa (2014), "Competencias locales en materia de educación, sanidad, servicios sociales y servicios de contenido audiovisual”, en M. Domingo Zaballos (coord.), Reforma del régimen local. La ley de racionalización y sostenibilidad de la Administración local: veintitrés estudios, Thomson Reuters Aranzadi, 2014, pp. 219-242.

- Zafra Víctor, Manuel (2014), “Doble inconstitucionalidad de la ley sobre racionalización y sostenibilidad de la autonomía local”, Cuadernos de Derecho local, n³ 34, pp. 49-70. 
